\title{
Specificity of Human Parietal Saccade and Reach Regions during Transcranial Magnetic Stimulation
}

\author{
Michael Vesia, ${ }^{1,2,5}$ Steven L. Prime, ${ }^{1,2,3}$ Xiaogang Yan, ${ }^{1,2}$ Lauren E. Sergio, ${ }^{1,2,3,5}$ and J. Douglas Crawford ${ }^{1,2,3,4,5}$ \\ ${ }^{1}$ Centre for Vision Research, ${ }^{2}$ Canadian Action and Perception Network, and ${ }^{3}$ Departments of Psychology, ${ }^{4}$ Biology, and ${ }^{5}$ Kinesiology and Health Science, \\ York University, Toronto, Ontario, Canada M3J 1P3
}

\begin{abstract}
Single-unit recordings in macaque monkeys have identified effector-specific regions in posterior parietal cortex (PPC), but functional neuroimaging in the human has yielded controversial results. Here we used on-line repetitive transcranial magnetic stimulation (rTMS) to determine saccade and reach specificity in human PPC. A short train of three TMS pulses (separated by an interval of 100 ms) was delivered to superior parieto-occipital cortex (SPOC), a region over the midposterior intraparietal sulcus (mIPS), and a site close to caudal IPS situated over the angular gyrus (AG) during a brief memory interval while subjects planned either a saccade or reach with the left or right hand. Behavioral measures then were compared to controls without rTMS. Stimulation of mIPS and AG produced similar patterns: increased end-point variability for reaches and decreased saccade accuracy for contralateral targets. In contrast, stimulation of SPOC deviated reach end points toward visual fixation and had no effect on saccades. Contralateral-limb specificity was highest for AG and lowest for SPOC. Visual feedback of the hand negated rTMS-induced disruptions of the reach plan for mIPS and AG, but not SPOC. These results suggest that human SPOC is specialized for encoding retinally peripheral reach goals, whereas more anterior-lateral regions (mIPS and AG) along the IPS possess overlapping maps for saccade and reach planning and are more closely involved in motor details (i.e., planning the reach vector for a specific hand). This work provides the first causal evidence for functional specificity of these parietal regions in healthy humans.
\end{abstract}

\section{Introduction}

Posterior parietal cortex (PPC) plays a critical role in the planning of actions (Goodale and Milner, 1992; Jeannerod et al., 1995; Andersen et al., 1997; Colby and Goldberg, 1999). In the monkey, effector-specific regions within PPC have been identified, including a lateral intraparietal area (LIP) specialized for saccadic eye movements and a more medial intraparietal area (MIP) and adjacent visual area V6A and area 5 for reaches (Kalaska et al., 1997; Snyder et al., 1997; Andersen and Buneo, 2002; Galletti et al., 2003; Fattori et al., 2009). In contrast, the effector specificity of human PPC remains controversial (Astafiev et al., 2003; Connolly et al., 2003; Fernandez-Ruiz et al., 2007; Hagler et al., 2007; Levy et al., 2007; Beurze et al., 2009; Filimon et al., 2009; Van Der Werf et al., 2010). Several functional magnetic resonance imaging (fMRI) studies have implicated a region around the medial intraparietal sulcus in saccades, reaching, and pointing preparation (see Fig. 1, circle). Other studies also suggest that a yet more medial-posterior region in superior parieto-occipital cortex (SPOC) may selectively encode contralateral manual actions (see Fig. 1, square). However, even in these studies, the degree of

Received March 24, 2010; revised May 27, 2010; accepted July 27, 2010.

This work was supported by grants from the Canadian Institutes of Health Research to J.D.C. and L.E. Sergio. M. Vesia was supported by an Ontario Graduate Scholarship, and J.D.C. holds a Canada Research Chair. We thank S. Sun for her technical assistance. We also thank W. E. Mcllroy and A. Singh for their technical support, and D. Y. Henriques and M. Fallah for helpful comments on this manuscript.

Correspondence should be addressed to M. Vesia, Centre for Vision Research, York University, 4700 Keele Street, Toronto, Ontario, Canada M3J 1P3. E-mail: mvesia@mac.com.

DOI:10.1523/JNEUROSCI.1644-10.2010

Copyright $\odot 2010$ the authors $\quad$ 0270-6474/10/3013053-13\$15.00/0 dissociation for eye and manual actions, compared to overlap, is less clear than in monkey PPC.

One explanation for this controversy may be related to the interpretative problems of $\mathrm{fMRI}$ in motor paradigms. First, the dissociation of saccade- and reach-related activity in monkey is relative, not absolute (Snyder et al., 1997, 2000; Calton et al., 2002), which might be difficult to distinguish in the blood oxygenation level-dependent (BOLD) fMRI signals (Logothetis, 2008). Second, eye and arm control signals may be intermingled for purposes other than direct control, such as eye-hand coordination (Pesaran et al., 2006). Third, the temporal resolution of fMRI limits the isolation of event-related information relative to the normal duration of a motor task. Fourth, given the physical constraints of the imaging environment, it is not possible to reach forward with a natural posture (Culham et al., 2006). Finally, different regions may perform specific computations (i.e., goal vs movement encoding), which might emerge only with more specific experimental designs (Fernandez-Ruiz et al., 2007).

An alternative, complementary approach is to disrupt cortical activity using transcranial magnetic stimulation (TMS). TMS can establish a causal link between the function of a particular cortical region at a specific stage of processing in a given task and normal behavioral measures in the healthy human (Hallett, 2000). For example, we recently used TMS to implicate a site close to the posterior part of the adjoining IPS situated over the angular gyrus (AG) (see Fig. 1, triangle) in computing the reach vector from hand and target position signals (Vesia et al., 2006, 2008), and others have shown effects on saccade performance in PPC (Oyachi and Ohtsuka, 1995; Müri et al., 1996; Nyffeler et al., 2005; 
Ryan et al., 2006). To our knowledge, TMS has not yet been used systematically to determine effector specificity in human PPC.

Here, we delivered a short train of three TMS pulses (separated by $100 \mathrm{~ms}$ ) to SPOC, midposterior intraparietal sulcus (mIPS), and AG (see Fig. 1) during the planning of spatially directed saccades and reaches (with either the left or right hand) and compared subjects' performance to baseline (nonstimulation) trials. We also used our visual feedback paradigm (Vesia et al., 2008) to test whether these regions encode only the reach goal or are involved in calculating the reach vector.

\section{Materials and Methods}

Subjects. Six right-handed (Oldfield, 1971) volunteers (four males and two females; aged 24-34 years) participated in each of the three experiments after providing written informed consent. All participants were in good health with normal to corrected-to-normal visual acuity and, according to self-report, without any known contraindications to TMS (Keel et al., 2001). All experimental procedures received ethical approval by the York University Human Participants Review Subcommittee.

Apparatus and stimuli. Subjects sat in a dark room with their head immobilized in an upright position by individual dental impressions (bite bars) supported by a four-ball-joint yoke that aligned the cyclopean eye position located midway between the two eyes with the central fixation cross. The experimental device was the same in all conditions and consisted of a modular bite bar/eye-tracking assembly fixed to a horizontal table surface in front of a cathode ray tube (CRT) monitor. Briefly, this custom-built assembly consisted of an EyeLink II eye-tracking system (SR Research) that was removed from its headband and fixed securely to the apparatus that held the bite bar, allowing access to the subject's scalp surface with the TMS coil. Subjects placed their index finger on an upraised bump ( $2 \mathrm{~cm}$ Lucite square; height, $0.5 \mathrm{~cm}$ ) on the table surface that could be located easily by touch. The start position of the hand was aligned with the central fixation cross but positioned $\sim 15 \mathrm{~cm}$ below in the frontal plane and placed on the table surface in the horizontal plane $10 \mathrm{~cm}$ away from the subject's torso. To prevent dark adaptation, the room was illuminated for $2 \mathrm{~s}$ after every third trial by direct lighting from two desk lamps controlled by a custom-made circuit board. All reaches, thus, were performed with no visual feedback of the limb.

Stimuli were presented on a CRT monitor (frame rate, $85 \mathrm{~Hz}$ ) in the frontal plane and viewed from a distance of $30 \mathrm{~cm}$. Fixation cross (subtended $0.8^{\circ}$ ), central letter cue (size, $0.8^{\circ}$ horizontal $\times 1.2^{\circ}$ vertical), and target stimuli (gray dot; diameter, $0.8^{\circ}$ ) were presented against a uniform black background. To ensure that all movements were performed without any visual reference other than fixation and target stimuli, a filter was placed over the screen to eliminate the faint luminance of the background and edges of the CRT image.

Localization of brain sites. To identify parietal loci of interest and monitor the TMS coil position, we used frameless stereotaxic neuronavigation (Brain Voyager TMS Neuronavigator; Brain Innovation). Before testing in the behavioral sessions, we acquired a T1-weighted, highresolution MRI from each participant using a 3T scanner (General Electric). We selected three different parietal stimulation sites in both the left and right hemispheres: (1) SPOC (Fig. 2A); (2) a region over the mIPS $(B)$, and (3) AG $(C)$. Both SPOC and mIPS sites were localized according to individually determined anatomical landmarks, whereas the AG site, similar to our previous studies (Vesia et al., 2006, 2008), was defined

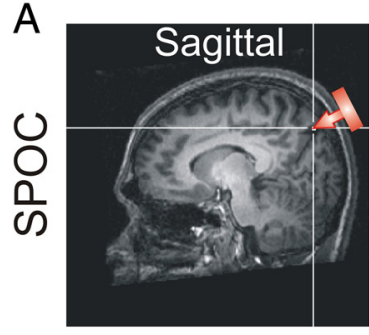

Right Hemisphere

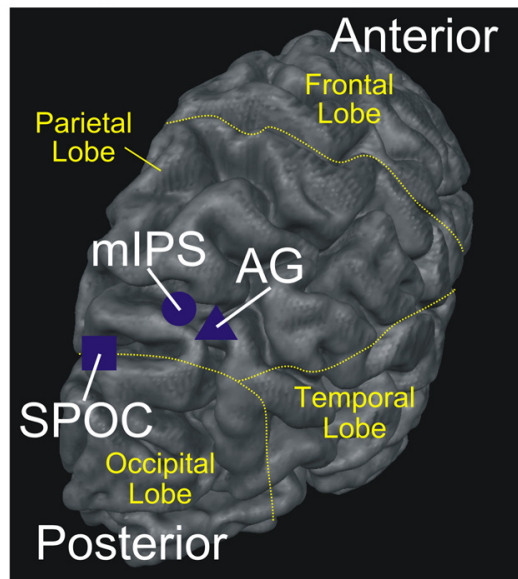

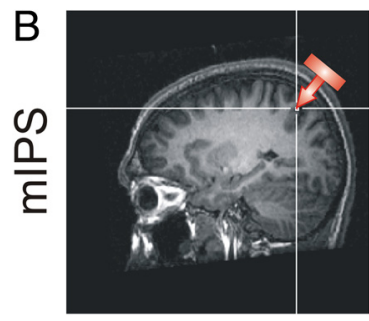
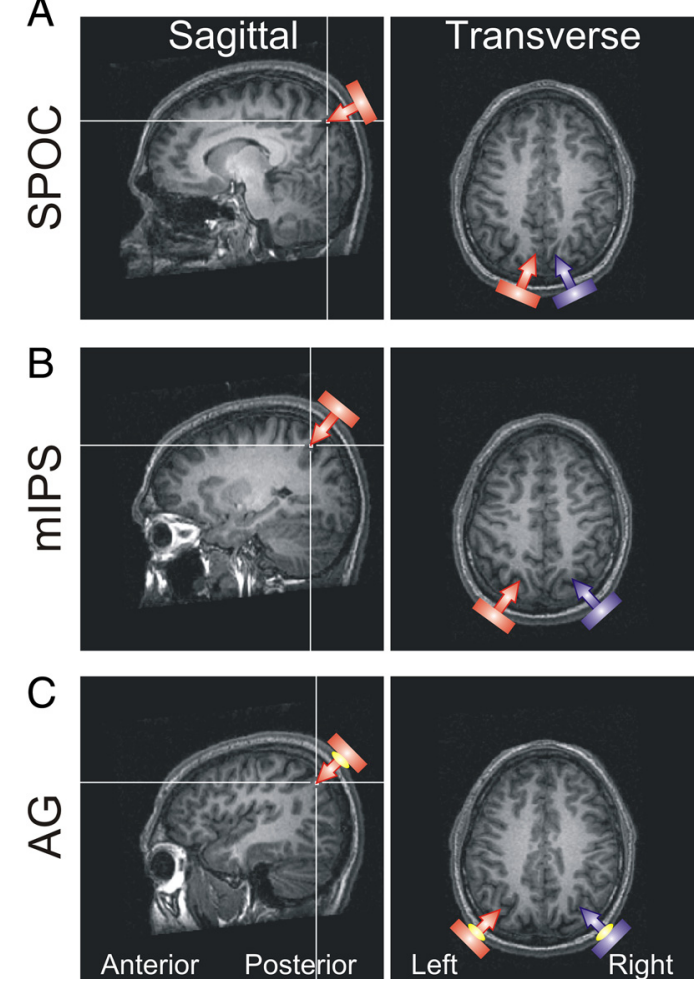

Figure 2. Neuroanatomical regions within PPC that were disrupted with rTMS for a typical subject. A-C, Anatomical sites were determined individually in each subject. Anatomical site of stimulation for left PPC (shown here) is indicated by the line intersection in the sagittal (left) and transverse (right) sections of T1-weighted MRI. Red and blue bars indicate position of the TMS coil in the left and right hemispheres for SPOC (top), mIPS (middle), and AG (bottom). Solid yellow circles indicate high-intensity signal markers that were placed on the subject's skull, using commercially available 10-20 EEG stretch caps in each participant. 
A

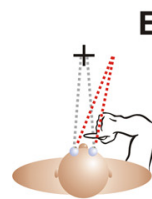

Experiment 1

$\ldots$

Saccade
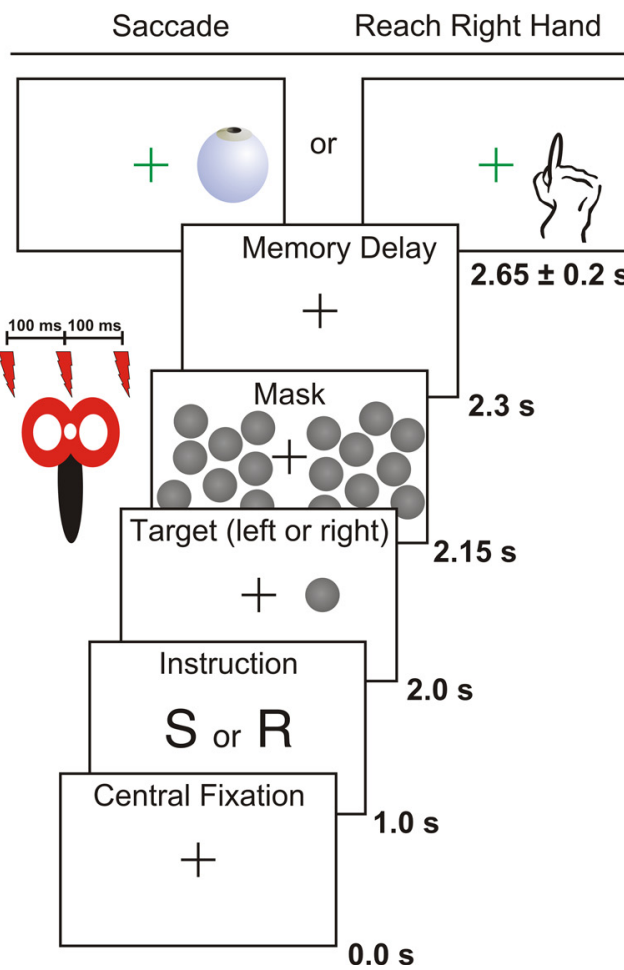

B Experiment 2

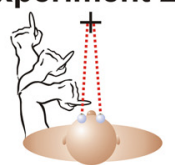

Reach Left Hand

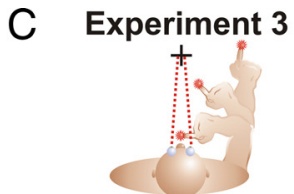

Reach Vision

$5.0 \mathrm{~s}$

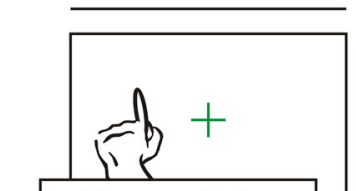

Memory Delay

$+$

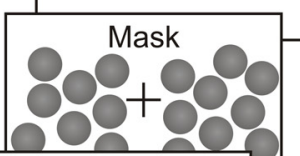

Target (left or right)

Target (left or right)

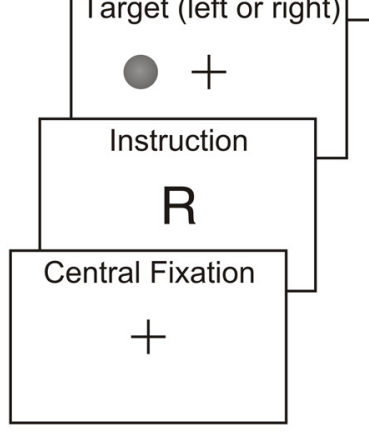

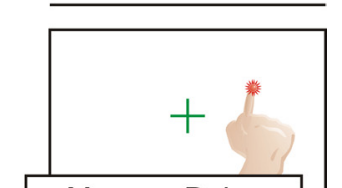

Memory Delay

$+$
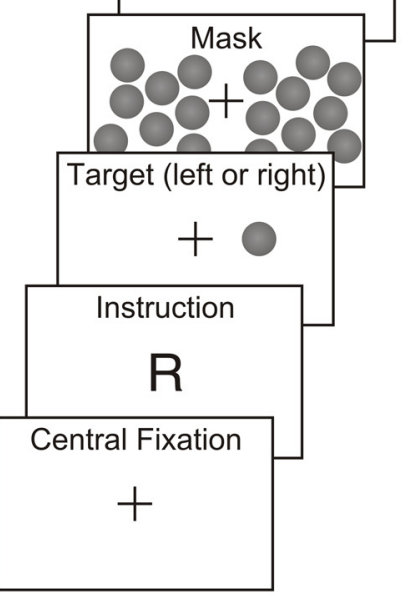

Figure 3. Experimental paradigms. A, Experiment 1, delayed movement task (left). Subjects fixated a central cross for $1 \mathrm{~s}$. Then, a central letter, Sor R, instructed subjects to plan either a saccadic eye or reach (with the right hand) movement, respectively. A peripheral dot was presented briefly for $150 \mathrm{~ms}$ to either the left or right of fixation. Note that the fixation cross was always straight ahead and aligned with the midsagittal plane of the head, but the targets (solid gray circle) varied from $30^{\circ}$ left to $30^{\circ}$ right of this fixation location. After this target extinguished, a mask blinked for $150 \mathrm{~ms}$ and an rTMS train $(10 \mathrm{~Hz}, 300 \mathrm{~ms}$ ) was delivered concurrently (on rTMS trials only) during the randomized, variable memory-delay period ( $500 \pm 200 \mathrm{~ms}$; range, $300-700 \mathrm{~ms}$ ). At this point, the central fixation cross changed color ("Go" signal) and signaled subjects either to saccade or reach to the remembered peripheral target location in complete darkness. Time between successive movements was 7 s. B, Experiment 2, delayed reach task with the left hand (middle). This was similar to the reach task in experiment 1, but required subjects to use the left hand instead. $\boldsymbol{C}$, Experiment 3, delayed reach task with visual feedback of the hand (right). This task was identical to the reach task in experiment 1 except that visual feedback of the hand was provided. Note that the labels on the schematic were not presented on the screen in the experiments.

according to P3 (left PPC) and P4 (right PPC) electrode positions on the 10-20 electroencephalogram (EEG) coordinate system (Herwig et al., 2003; Okamoto et al., 2004) and identified a priori with high-intensity signal markers on the subject's skull (Fig. $2 C$, solid yellow circle) using commercially available 10-20 EEG stretch caps for 20 channels (ElectroCap International) in each participant.

Average normalized coordinates for each parietal stimulation site according to standardized stereotaxic space (Talairach and Tournoux, 1988) for all six subjects are reported below. In particular, SPOC (Fig. $2 \mathrm{~A}$, top) was defined as a region situated along the medial surface of the parietal lobe, medial to the intraparietal sulcus, anterior to the parietooccipital sulcus, and posterior to the subparietal sulcus; this region includes generally the superior end of the parieto-occipital sulcus, as well as the regions immediately anterior (in the precuneus) and posterior (in the cuneus) to the sulcus (group mean \pm SD: left Talairach coordinates (TCs), $x=-10.3 \pm 3.7, y=-80.2 \pm 6.9, z=42.2 \pm 3.8$; right TCs, $x=$ $9.5 \pm 3.3, y=-80.6 \pm 5.8, z=44.2 \pm 5.7$ ] (Culham et al., 2008). In contrast, the more anterior-lateral site, mIPS (Fig. $2 \mathrm{~B}$, middle), was defined as a region located over the midposterior portion of intraparietal sulcus, and most likely includes both the lateral and medial banks of the intraparietal sulcus (left TCs, $x=-22.2 \pm 3.5, y=-64.8 \pm 5.9, z=$ $41.8 \pm 4.2$; right TCs, $x=23.8 \pm 2.6, y=-62.2 \pm 4.4, z=41.2 \pm 3.4)$. Finally, the dorsal-lateral site, AG (Fig. $2 C$, bottom), included Brodmann area 39, adjacent cortex in the superior and inferior parietal lobule, a site that is situated over a part of the angular gyrus in the inferior parietal lobule and close to a posterior part of the adjoining intraparietal sulcus, and is consonant with cortical regions underlying these electrode positions reported previously (left TCs, $x=-40.5 \pm 4.6, y=-66.8 \pm 6.4$, $z=41.3 \pm 4.2$; right TCs, $x=36.3 \pm 5.6, y=-70.5 \pm 5.9, z=42.6 \pm$ 2.8) (Herwig et al., 2003; Okamoto et al., 2004; Vesia et al., 2006, 2008; Koch et al., 2008; Prime et al., 2008). The coordinates for these three locations correspond well with other neuroimaging and lesion loci studies identifying activation foci for pointing, reaching, and saccadic eye movements in human parietal areas (for review, see Grefkes and Fink, 2005; Culham et al., 2006; Culham and Valyear, 2006) (Sereno et al., 2001; Astafiev et al., 2003; Connolly et al., 2003; Medendorp et al., 2003; Karnath and Perenin, 2005; Prado et al., 2005; Fernandez-Ruiz et al., 2007; Hagler et al., 2007; Levy et al., 2007; Tosoni et al., 2008; Beurze et al., 2009; Filimon et al., 2009; Gallivan et al., 2009), and allow for a comparison between our stimulation sites and other TMS, patient, and fMRI studies (see Discussion) (see Fig. 11).

Control site, sham, and baseline conditions. Three additional control experiments were conducted to yield estimates of nonspecific effects of repetitive TMS (rTMS). First, we assessed performance after stimulation of the vertex ( $\mathrm{Cz}$ according to the 10-20 EEG coordinate system). Specifically, the vertex was defined as a point midway between the inion and nasion and equidistant from the left and right intertragal notches. Second, we conducted "sham" trials in which the coil was held close to the subject's scalp surface, but angled away so that no current was induced in the brain for both left and right parietal hemispheres. Last, we included a 
baseline "no rTMS" condition where subjects received no stimulation while performing the task. To eliminate potential rTMS aftereffects on cortical activity that outlast the period of direct stimulation (Pascual-Leone et al., 1994; Wang et al., 1996; Levkovitz et al., 1999; Siebner and Rothwell, 2003; Siebner et al., 2009), we also interleaved these nonstimulation trials with rTMS trials to provide an unbiased measure on behavioral performance. The mean directional, end-point error and variability (elliptical area) in nonstimulation trials for both saccade and reach tasks were used as a baseline when comparing stimulation conditions across subjects and tasks.

TMS protocol. The rTMS train $(10 \mathrm{~Hz}, 300$ ms; analogous to three single pulses of TMS separated by $100 \mathrm{~ms}$ ) was delivered using a MagStim Rapid ${ }^{2}$ stimulator and a $70 \mathrm{~mm}$ figure-of-eight coil held in position on the scalp surface by an articulated coil stand (MagStim). For all sites, the TMS coil was held tangential to the scalp surface along a parasagittal line with the handle pointing downward. The center of the coil (stimulation locus) was continuously monitored to be over the site of interest. It has been suggested that the locus of TMS stimulation has a spatial resolution of $\sim 0.5-1 \mathrm{~cm}$ (Brasil-Neto et al., 1992; Wilson et al., 1993) with an estimated penetration depth of $\sim 2 \mathrm{~cm}$ (Epstein et al., 1990; Rudiak and Marg, 1994), reflecting stimulation of the underlying cortex near the gray-white junction (Epstein et al., 1990) (cf. Siebner et al., 2009; Wagner et al., 2009). Some evidence, however, also suggests that rTMS may influence remote interconnected regions outside the stimulation locus (Sack, 2006; Bestmann et al., 2008; Driver et al., 2009; Ruff et al., 2009); accordingly, the proximity between SPOC, mIPS, and AG robustly controlled for the spatial specificity of rTMS-induced effects. Custom software externally triggered the rTMS train at peripheral target offset during the memory delay period for the stimulation conditions only (see the experimental paradigm below in Experimental procedure).

It has been argued that the motor threshold does not adequately represent the excitability of nonmotor areas of the brain (Stewart et al., 2001; Boroojerdi et al., 2002; Robertson et al., 2003) (cf. Stokes et al., 2005; Oliver et al., 2009). Accordingly, the intensity of magnetic stimulation was fixed to $60 \%$ of the stimulator output, similar to a number of previous TMS studies of PPC (Lewald et al., 2002; Dambeck et al., 2006; Vesia et al., 2006, 2008; Buelte et al., 2008; Prime et al., 2008). This protocol yielded an individual mean resting motor threshold (rMT) of 104\% (SD, $2.08 \%$; range, $101-108 \%$ ) across the sessions and subjects. The rMT was defined as the intensity required to produce a visible contraction of the intrinsic hand muscles for $50 \%$ of the time at the minimally required stimulator intensity with the coil positioned over the hand area of the primary motor cortex (M1). The rMT was measured separately for left and right M1 and was not statistically different $\left(t_{(5)}=2.07 ; p=0.09\right.$ ). This procedure was repeated for each subject before all experimental sessions. The frequency, intensity, and duration of the rTMS train were well within safe limits (Wassermann, 1998; Machii et al., 2006; Rossi et al., 2009). Earplugs were provided to dampen the noise associated with the discharge from the TMS coil. After completing the experiment, five participants reported mild neck pain, which they attributed to the prolonged period of sitting with their head immobilized by the bite bar. None of the participants reported any undesirable side effects as a result of the stimulation except for two participants who reported mild headaches.

Experimental procedure. Three separate experiments were performed. To familiarize subjects with the paradigm, a practice session equivalent to one experimental block was conducted before each actual experiment without stimulation.

Experiment 1 aimed to identify effector selectivity for eye and arm movements in selected human parietal regions (Fig. 3A). At the start of each block of trials, subjects fixated at a central cross in the middle of the screen and placed their dominant right hand at the start position on the table surface. Next, the cross at fixation changed to a letter, "S" or "R," instructing subjects to plan either a saccade or reach, respectively. Then, a brief peripheral target appeared for $150 \mathrm{~ms}$ at one (randomly selected) of six possible horizontal eccentricities $\left(10,20\right.$, or $\left.30^{\circ}\right)$ to either the left or right of the central fixation cross. Subsequently, a mask $\left(65^{\circ}\right.$ horizontal $\times$ $50^{\circ}$ vertical; eccentricity of dot, $0.8^{\circ}$; density, $0.5^{\circ}$ dots $/ \mathrm{deg}^{2}$ ) flashed briefly for $150 \mathrm{~ms}$ to reduce the possibility of visual persistence immediately after the target display, while subjects maintained central fixation, and ensured that subjects were not relying on any afterimage of the target display to aid performance. Additionally, time locked to the onset of the mask, three pulses of rTMS were delivered (analogous to 0, 100, and 200 ms after the peripheral target extinguished) on rTMS trials only. The timing of the pulses are consistent with both previous TMS and magnetoencephalography work from our lab (Vesia et al., 2006, 2008; Ren et al., 2008) and a recent electroencephalography study that found peak activation over parietal areas $\sim 200 \mathrm{~ms}$ after visual stimulus onset (Bernier et al., 2009). This was followed by a randomized memory delay interval (500 $\pm 200 \mathrm{~ms}$; range, 300-700 ms) during which subjects continued to maintain both ocular and manual fixation. After the delay period, the central fixation cross changed color and cued subjects to execute either a saccadic eye movement (see Fig. $4 A, C$ ) or an open-loop reach movement $(B, D)$ to the remembered peripheral target. The duration of a trial was $5 \mathrm{~s}$, followed by a $2 \mathrm{~s}$ intertrial interval.

In each block, all peripheral target locations were repeated five times in a pseudorandom order to each of the six peripheral targets [three in the left visual hemifield (LVF) and three in the right visual hemifield (RVF)] for each task. Two blocks were collected for the baseline (no rTMS), control (vertex and parietal sham rTMS), and test (parietal rTMS with interleaved no rTMS trials) conditions with the right hand. To minimize fatigue and TMS exposure, the site of stimulation (parietal rTMS, ver- 
tex), including sham (left parietal sham, right parietal sham) and baseline conditions (nonstimulation), order was counterbalanced across subjects over two experimental sessions. Consecutive testing sessions were separated by a minimum of $24 \mathrm{~h}$. A total of 1200 trials ( 600 for each task) were performed over the multiple sessions (two blocks of 30 saccade and 30 reach trials for test, control, and baseline conditions).

Experiments 2 and 3 were conducted several months after experiment 1. Similar to experiment 1 , the order of blocks was counterbalanced across subjects over two experimental sessions for each study and separated by a minimum of $24 \mathrm{~h}$. In addition, each study was separated by a minimum of 2 weeks.

Experiment 2 was designed to test for any rTMS-induced effects on memory-guided reach accuracy and precision while subjects were planning reach movements with the left hand. The same sequence of stimuli was used for experiment 2 except that the saccade cue was not presented. The reach task was similar to that in experiment 1 , but now required subjects to use the left hand instead (Fig. $3 B$ ). In this experiment, we collected one block, which consisted of 10 trials in a pseudorandom order to each of the six reach targets in the periphery ( 60 trials) for baseline (nonstimulation) and parietal rTMS conditions with the left hand, for a total of 420 trials.

The goal of experiment 3 was to identify parietal regions modulated by visual feedback of the hand during reaching (Vesia et al., 2008). This was identical to the reach task in experiment 1 , but now provided visual feedback of the hand (Fig. 3C). A dimly lit, red light-emitting diode (diameter, $\sim 7 \mathrm{~mm}$ ) was attached to the right index finger of subjects and illuminated during the reach movement, thus providing visual feedback of the hand only. We collected one block of 60 trials for both baseline (nonstimulation) and parietal rTMS conditions with visual feedback of the right hand, for a total of 420 trials.

Data acquisition and analysis. The two-dimensional (2D) coordinates of right eye movements relative to a digitized screen were recorded using the modified EyeLink II eye-tracking system (sampling rate, $500 \mathrm{~Hz}$; accuracy, $\sim 0.5^{\circ}$ ) and then converted to $2 \mathrm{D}$ angular displacement. The eye-tracking system was recalibrated before each block by having subjects fixate nine targets of known position on the screen. Kinematic data of reach movements were obtained by localizing the three-dimensional position of infrared light-emitting diodes taped to the lateral tip of index finger (Optotrak 3020; Northern Digital) (sampling rate, $200 \mathrm{~Hz}$; accuracy, $\sim 0.2 \mathrm{~mm}$ ). Example measures of eye and hand trajectories for a typical subject are illustrated in Figure 4, $C$ and $D$, respectively.

We performed several complementary analyses on saccade- and reachrelated kinematic measures, using methods described previously (Vesia et al., 2006, 2008). Briefly, movement onset and offset were defined as the point at which the tangential velocity exceeded or fell and remained above/below $5 \%$ of peak velocity, respectively. We defined reaction time as the interval between "Go" cue and movement onset. Movement time was obtained by subtracting the movement onset from the respective movement offset. Movement accuracy and precision were derived from the parameters of $95 \%$ confidence ellipses fit to eye and hand position distributions measured at movement offset. Figure 5 shows examples of ellipses fit to control (nonstimulation) and rTMS end-point distributions of the eye and hand for two target positions for a representative subject. Constant error was calculated by taking the signed difference between the horizontal and vertical center parameters of movement ellipses and each target location. Variable error was measured using the area of these ellipses, and results significantly different than control (nonstimulation) values are reported. Statistical reliability of differences between mean constant errors, elliptical areas, and mean reaction and movement times for both saccade and reach were tested using repeatedmeasures ANOVA and Tukey's post hoc tests. Threshold for statistical significance was set at 0.05 . For conciseness, only significant findings are reported.

\section{Results}

\section{Saccade and reach accuracy}

As a first step, we analyzed the constant error pattern of end points for the saccade and reach tasks. Parietal rTMS produced significant constant errors only in the horizontal component (as

\section{Subject 1 No TMS $\square$ Left PPC Right PPC}

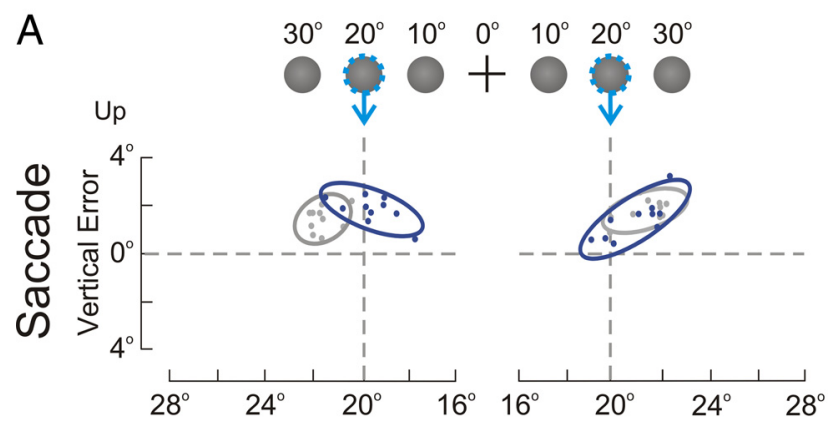

B

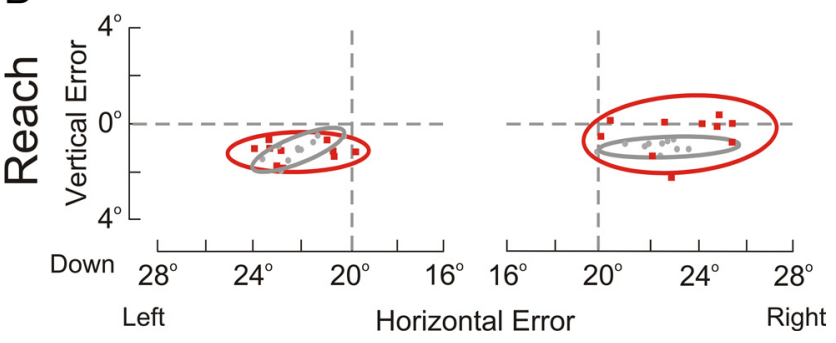

Figure 5. $\quad \boldsymbol{A}, \boldsymbol{B}$, A typical subject's $95 \%$ confidence elliptical fits to the scatter of the eye or fingertip end points in the frontal plane, for nonstimulation trials (solid gray ellipse or circle) and left (solid red ellipse or square) and right (solid blue ellipse or circle) PPC stimulation trials for a $20^{\circ}$ peripheral target in the LVF (left) and RVF (right), for a representative block of trials in the saccade task $(\boldsymbol{A})$ and reach task $(\boldsymbol{B})$, respectively. Given that targets were aligned horizontally with the fixation location, subjects were more consistent in estimating the vertical position of the target rather than its horizontal position, as evident by the long, narrow, 95\% confidence ellipses.

described in detail below). Significant errors were not observed in the vertical component (all $p$ values $>0.05$ ); thus, these data are not shown. This bias effect in accuracy most likely reflects an influence of the experimental configuration, in which the targets were aligned horizontally with the fixation location. As observed in previous studies (Bock, 1986; Henriques et al., 1998; Henriques and Crawford, 2000; Medendorp and Crawford, 2002; Pouget et al., 2002; Poljac and Van Den Berg, 2003), baseline horizontal errors for reaches to peripheral targets are biased relative to gaze-position angle; therefore, any rTMS-induced errors reported here are relative to these baseline errors (supplemental Fig. S1, available at www.jneurosci.org as supplemental material). To simplify the data description and focus on rTMSinduced errors, henceforth we show data where baseline errors for the same task and visual target were subtracted. This is illustrated in Figure 6 for saccades $(A-C$, left) and reaches with the left ( $D-F$, middle) and right hand $(G-I$, right). These plots show the change in horizontal error for all targets for each parietal site in left (solid red square and line) and right (solid blue circle and line) hemisphere (relative to baseline performance) for saccade and reach tasks. In this way, one can compare the mean horizontal errors between different parietal stimulation sites and saccades and reaches.

As shown in Figure 6, $A-C$, the effect of rTMS on saccade accuracy depended on both the site of stimulation and the visual hemifield (target location, $F_{(5,25)}=14.93, p<0.001$; stimulation condition, $F_{(6,30)}=5.01, p=0.001$; target location by stimulation condition interaction, $\left.F_{(30,150)}=4.92, p<0.001\right)$. Stimulation of right mIPS (Fig. $6 B$, solid blue circle) and right AG (Fig. $6 C$, solid blue circle) produced a rightward shift (i.e., hypometria) in mean horizontal end points for leftward saccades com- 


\section{Accuracy}

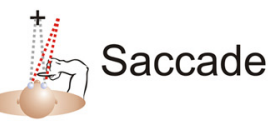

$30^{\circ} 20^{\circ} 10^{\circ} 0^{\circ} 10^{\circ} 20^{\circ} 30^{\circ}$

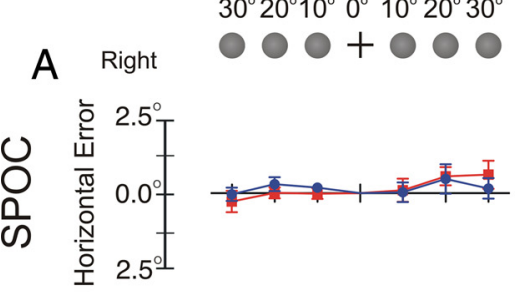

$\mathrm{B}$
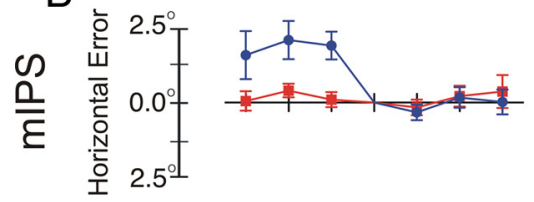

C

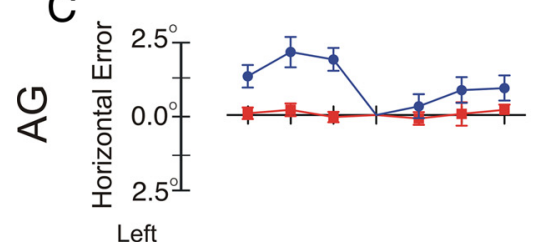

Reach (LH)

$30^{\circ} 20^{\circ} 10^{\circ} 0^{\circ} 10^{\circ} 20^{\circ} 30^{\circ}$
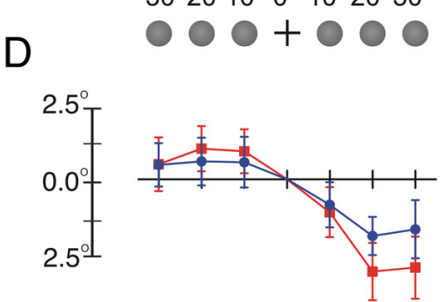

$\mathrm{E}$

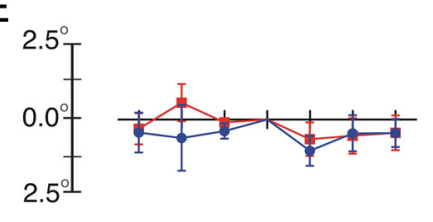

$\mathrm{F}$

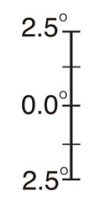

Left PPC Right PPC
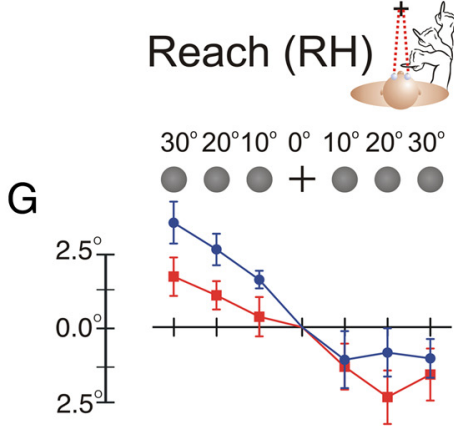

$\mathrm{H}$

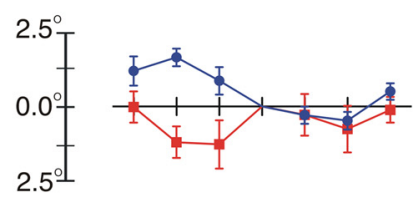

।

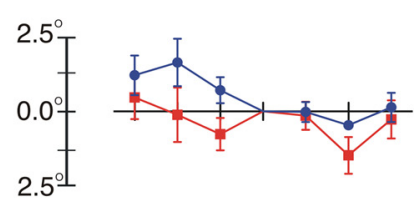

Figure 6. Saccade and reach accuracy plots. $\boldsymbol{A}-\boldsymbol{I}$, The magnitude of the rTMS-induced effects on horizontal error (relative to baseline no rTMS condition) is plotted for saccades (A-C, left) and reaches with the left hand $(\mathrm{LH})(\mathbf{D}-\boldsymbol{F}$, middle) and right hand (RH) $(\mathbf{G}-\mathbf{I}$, right) for all subjects $(n=6)$. These plots show the change in horizontal error for all targets for the SPOC (top), $\mathrm{mIPS}$ (middle), and AG (bottom) in the left PPC (solid red square and line) and right PPC (solid blue circle and line). Error bars represent SE.

pared with stimulation of other parietal sites (solid blue circle) ( $p<0.001$ in all comparisons). Magnitudes of this rightward shift were similar across the three leftward target eccentricities during rTMS of both the right mIPS (mean horizontal error relative to baseline $\pm \mathrm{SEM}$, right $\mathrm{mIPS}, 10^{\circ}=1.91 \pm 0.47^{\circ} ; 20^{\circ}=$ $2.09 \pm 0.64^{\circ} ; 30^{\circ}=1.59 \pm 0.81^{\circ} ;$ LVF target eccentricities) and right $A G\left(\right.$ right $A G, 10^{\circ}=1.86 \pm 0.38^{\circ} ; 20^{\circ}=2.11 \pm 0.51^{\circ} ; 30^{\circ}=$ $1.31 \pm 0.38^{\circ} ; \mathrm{LVF}$ target eccentricities $)$. In contrast, no significant bias occurred in saccades after stimulation of the left mIPS, left AG, or either side of SPOC (Fig. 6A) (all $p$ values $>0.05$ ).

We repeated the same analysis for reach accuracy as shown in Figure $6, D-F$, for the left hand and Figure $6, G-I$, for the right hand. Reach accuracy only was affected by stimulation of SPOC (reach left hand, target location, $F_{(5,25)}=4.39, p=0.005$; stimulation condition, $F_{(6,30)}=4.89, p=0.001$; target location by stimulation condition interaction, $F_{(30,150)}=0.85, p=0.69$; reach right hand, target location, $F_{(5,25)}=6.36, p<0.001$; stimulation condition, $F_{(6,30)}=3.11, p=0.02$; target location by stimulation condition interaction, $\left.F_{(30,150)}=4.08, p<0.001\right)$. Specifically, we noted a significant leftward deviation of end points toward central fixation after left hemispheric stimulation of SPOC (Fig. $6 D$, solid red square) for the two rightmost targets in the RVF (contralateral to stimulation) for reaches with the left hand (left SPOC, $10^{\circ}=1.09 \pm 0.84, p=0.99 ; 20^{\circ}=3.08 \pm 0.96^{\circ}$, $p=0.03 ; 30^{\circ}=2.95 \pm 1.03^{\circ}, p=0.05$, RVF target eccentricities). Conversely, during right-hand reaching, rTMS over right SPOC (Fig. 6G, solid blue circle) deviated the reach end points rightward toward central fixation for the two leftmost targets in the contralateral LVF (right SPOC, $10^{\circ}=1.59 \pm 0.29, p=0.83$; $20^{\circ}=2.61 \pm 0.53^{\circ}, p=0.01 ; 30^{\circ}=3.49 \pm 0.69^{\circ}, p<0.0001 ; \mathrm{LVF}$ target eccentricities). Overall, the pattern of reach errors suggested that stimulation of both left and right SPOC for reaches with either hand, systematically deviated end points toward visual fixation, regardless of visual hemifield (although these effects were not always significant).

In summary, rTMS of right mIPS and right AG produced a horizontal hypometria in leftward saccades, whereas rTMS to both sides of SPOC produced horizontal hypometria for both leftward and rightward reach targets, and for both hands.

\section{Saccade and reach precision}

Next, we examined whether rTMS affected saccade and reach end-point precision. Again, these were derived from the area of $95 \%$ confidence ellipses of the scatter of the eye or fingertip at movement end (see Materials and Methods) (Fig. 5). Overall, the mean elliptical area was calculated by averaging across the ellipse parameters fit to each subject for every target. To simplify the analyses and increase statistical power, we then merged data for all targets in each visual hemifield (no differences were found between the three peripheral target locations; all $p$ values $>0.05$ ). Statistical comparison of parietal stimulation and baseline nonstimulation trials indicated that the effect of rTMS on reach precision depended on both the parietal site and visual hemifield (reach left hand, visual hemifield, $F_{(1,5)}=20.68, p=0.006$; stimulation condition, $F_{(6,30)}=2.11, p=0.08$; visual hemifield by stimulation condition interaction, $F_{(6,30)}=3.45, p=0.01$; reach right hand, visual hemifield, $F_{(1,5)}=1.61, p=0.26$; stimulation condition, $F_{(6,30)}=2.97, p=0.02$; visual hemifield by stimulation condition interaction, $\left.F_{(6,30)}=4.81, p<0.001\right)$.

To focus on stimulation-induced errors, we plot only rTMSinduced errors relative to baseline precision for the same task by expressing mean elliptical area with parietal stimulation as a ratio of the mean baseline nonstimulation. Figure 7 illustrates the precision ratio for reaches with the left $(A-C)$ and right hand $(D-F)$. 


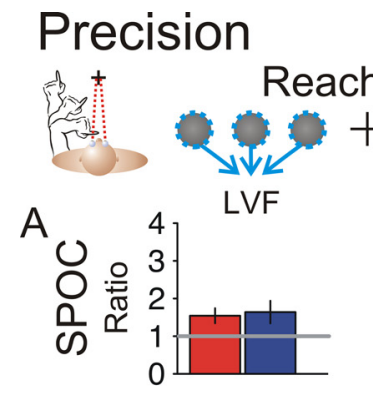

B

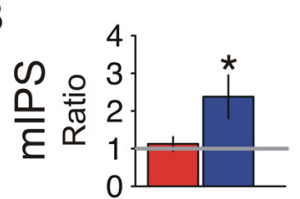

C

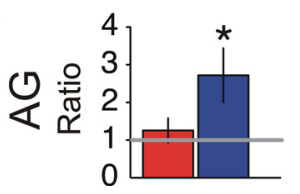

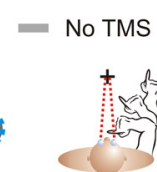

Left PPC

Right PPC

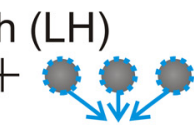

RVF

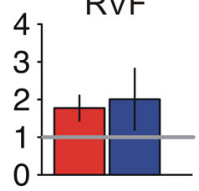

D

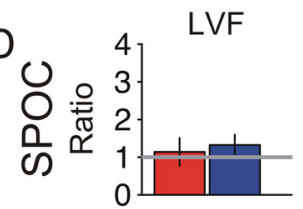

E
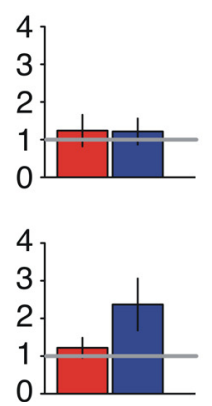

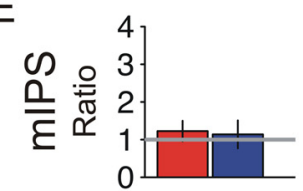

F

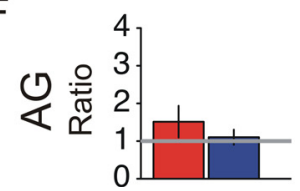

To summarize, rTMS of mIPS and AG reduced precision for reaches with the contralateral hand toward the contralateral visual hemifield, but induced no effects on saccade precision; moreover, rTMS of SPOC affected neither saccade nor reach precision.

\section{Limb specificity}

To directly investigate limb-specific effects, we calculated the ratio of ellipse area between the rTMS and control data and then plotted this ratio for the contralaterallimb data (ordinate) as a function of ipsilateral-limb data (abscissa) in each subject (Fig. $8 A-C$ ). This was performed separately for the ipsilateral (solid white circle) and contralateral (solid black circle) visual hemifields for SPOC (Fig. $8 \mathrm{~A}$ ), mIPS $(B)$, and AG $(C)$. For regions that show limb-unspecific responses, the data should cluster equally along the diagonal dotted line, whereas for regions that show contralateral-limb specificity the data should be above this line. Individual subjects showed considerable variability in these plots, but a progressive shift in the limb selectivity distribution from stimulation of the more posterior-medial to the more anterior-lateral regions was ob(RH) (D-F, right, experiment 1). The mean elliptical area was merged for all targets in each visual hemifield for each subject, and then averaged across all six subjects. Bar graphs plot the precision ratio (mean elliptical area with rTMS as a ratio of the mean baseline no rTMS condition) for both left PPC (solid red bar) and right PPC (solid blue bar) stimulation, for the SPOC (top), mIPS (middle), and AG (bottom) in the LVF (left) and RVF (right). Solid gray line (baseline no rTMS condition) indicates a ratio value equal to one and reflects identical elliptical areas, whereas values greater than this value indicate that parietal rTMS increased end-point variability. Asterisks indicate values showing significant differences $\left({ }^{*} p<0.05\right)$ using Tukey's post hoc tests. Error bars represent SE.

The mean precision ratio for left (solid red bar) and right (solid blue bar) hemispheric stimulation is shown for each parietal site in the LVF (left panels) and RVF (right panels). For reference, ratio values greater than one (i.e., above solid gray line) indicate that rTMS increased end-point variability, thereby interfering with the putative neural processes underlying saccade or reach planning mediated by stimulating the brain region of interest.

Stimulation of right mIPS $(p=0.01)$ and right AG $(p=$ 0.001 ) produced a significant increase in end-point variability only for reaches with the left hand in the LVF (Fig. $7 B, C$, respectively, solid blue bar, left). Conversely, left mIPS ( $p=0.03)$ and left AG ( $p=0.03)$ stimulation significantly increased end-point variability only for reaches with the right hand in the RVF (Fig. $7 E, F$, respectively, solid red bar, right). Thus, both sides of these two regions were spatially and limb selective in relation to both the target location (or movement direction) and limb used; that is, rTMS induced greater errors on precision for the contralateral than for the ipsilateral hand and visual hemifield. Strikingly, the precision ratio also indicated that stimulation of MIPS and AG in both hemispheres increased end-point variability nearly threefold for reaches toward the contralateral visual hemifield with the contralateral limb [precision ratio \pm SE, reach left hand (LVF), right mIPS, $2.38 \pm 0.57$; right $A G, 2.72 \pm 0.72$; reach right hand (RVF), left mIPS, $3.19 \pm 0.71$; left AG, $2.72 \pm 0.53$ ]. Stimulation of either side of SPOC, however, did not significantly increase end-point distributions for reaches with either hand (Fig. $7 A, D$, top row) (all $p$ values $>0.05$ ). A similar analysis revealed no significant effect of parietal stimulation on saccade precision (saccade, visual hemifield, $F_{(1,5)}=0.19$, $p=0.68$; stimulation condition, $F_{(6,30)}=1.76, p=0.14$ ) (supplemental Fig. S2, available at www.jneurosci.org as supplemental material). served. In particular, there was a clustering of data points along the diagonal (equality) line in SPOC for both visual hemifields (Fig. $8 A$ ), but for mIPS $(B)$ the contralateral visual hemifield data (solid black circle) tended to shift above the diagonal, and for AG $(C)$, data from both visual hemifields were shifted above the diagonal, indicating progressively increasing limb specificity.

To summarize these results, we calculated a limb specificity index (the difference between the precision ratio for trials with the contralateral limb and ipsilateral limb divided by their sum) in both the ipsilateral and contralateral visual hemifields (supplemental Fig. S3, available at www.jneurosci.org as supplemental material). This analysis revealed a statistically significant contralateral-limb bias for AG and mIPS, but not SPOC. This statistical analysis also confirmed that the effect was visualhemifield-dependent for mIPS but not AG. Thus, mIPS and AG, but not SPOC, showed a contralateral-limb-related bias.

\section{Effect of visual feedback of the hand}

In a previous study (Vesia et al., 2008), we showed that visual feedback of the hand before or during the reach negated any errors induced by stimulation over AG. More specifically, in this study we assumed that visual feedback of the hand would counteract errors that may have perturbed the internal estimate of hand position or hand and target position signals used to calculate the reach vector. In contrast, visual feedback of the hand could not counteract errors that perturbed the internal estimate of the goal, given that it provided no novel information about target location. Here we aimed to repeat this result for AG and test these predictions for mIPS and SPOC with the right hand in the same subjects. Based on previous fMRI results that suggest that SPOC encodes the goals of actions, rather than movements (Fernandez-Ruiz et al., 2007), we predicted that visual feedback of the hand would not counteract rTMS-induced errors in this 
region, whereas this visual information either could or could not modulate errors in mIPS.

To perform this analysis, it was necessary first to identify statistically significant rTMS-induced effects on reach performance without visual feedback of the hand (experiment 1), and then test whether visual feedback decreased these errors (experiment 3). As we have shown above, rTMS produced different effects, depending on the region. Sometimes rTMS produced significant effects on accuracy, sometimes on precision, and sometimes it produced no significant effects. Thus, it was not possible here to provide direct quantitative comparisons in the same measure between regions. Instead, we used the general principle of the test to determine whether the significant effects in each region were modulated by visual feedback, and then compared this result between regions.

First, we repeated the same analysis on accuracy and precision in the same subjects, but for reaching with visual feedback of the right hand instead. Again, parietal rTMS affected reach accuracy (reach vision, accuracy, target location, $F_{(5,25)}=5.24, p=0.002$; stimulation condition, $F_{(6,30)}=7.53, p<0.001$; target location by stimulation condition interaction, $F_{(30,150)}=1.21, p=0.23$ ) (Figure $9 A-C$ ), but did not affect reach precision in any parietal site (reach vision, precision, visual hemifield, $F_{(1,5)}=0.55, p=$ 0.49 ; stimulation condition, $F_{(6,30)}=1.25, p=0.31$ ) (Figure $9 D-F)$. As in experiment 1 , rTMS of right SPOC produced a significant rightward deviation of end points toward central fixation for the two leftmost targets in the contralateral LVF (right SPOC, $10^{\circ}=1.05 \pm 0.43, p=0.99 ; 20^{\circ}=2.11 \pm 0.86^{\circ}, p=0.01$; $30^{\circ}=2.07 \pm 0.85^{\circ}, p<0.014$; LVF target eccentricities) (Fig. $9 A$ ). Overall, stimulation to both sides of SPOC, albeit not always significant, systematically deviated horizontal reach end points toward visual fixation, regardless of visual hemifield (Fig. 9A), whereas stimulation to either side of mIPS $(B)$ and AG $(C)$ did not affect reach accuracy. Thus, a similar pattern of horizontal reach errors and reach precision was induced by rTMS of SPOC only when reaching with visual feedback of the hand.

Next, we directly compared the effects of visual feedback of the hand in cases where rTMS produced a significant effect in experiment 1 (without visual feedback). Again, for mIPS and AG, the only significant $r$ TMS-induced effect for right-hand reaching was for precision (the inverse of ellipse area) with the contralateral hemisphere (left PPC) in the contralateral visual hemifield (RVF). Figure 7, $E$ and $F$, shows the average ratios (across subjects) of ellipse area for reach scatter with the right hand after stimulation of left mIPS $(E)$ and left AG $(F)$, respectively, for reaching without visual feedback of the hand (solid red bar, right panels) (experiment 1), and when visual feedback was provided (Fig. 9E, F, solid red bar, right panels) (experiment 3). Consistent with our previous results (Vesia et al., 2008), the increase in reach end-point variability induced by AG stimulation significantly decreased with visual feedback of the hand $(p=0.02)$, resulting in an ellipse ratio that was not significantly different from one ( $p=$ 0.99 ), i.e., similar to controls. Once again, mIPS followed a similar pattern, showing a significant decrease in the rTMS-induced effect during visual feedback $(p=0.01)$, again decreasing the precision ratio to near one ( $p=0.99)$. This suggests that rTMS over these more anterior-lateral regions disrupts the reach vector or, alternatively, the sense of initial hand position that is used to calculate this vector.

For SPOC, we used accuracy (relative to baseline nonstimulation), which for right-hand reaching provided significant results only for right hemispheric stimulation. The entire pattern of reach errors across targets for rTMS to right SPOC, averaged across subjects, is shown in Figure 10 for reaches without (open gray circle) (experiment 1 ) and with (filled black square) (experiment 3) visual feedback of the right hand. As predicted, vision of the hand position did not counteract the rTMS-induced effect on reach performance in SPOC ( $p$ values for each target $>0.05$ ). This suggests that the errors induced during rTMS of SPOC are not related to the incorporation of hand position signals into the calculation of the reach vector, and thus instead may be goal related.

\section{Control experiments, movement time, and latency}

To rule out any nonspecific rTMS-induced effects, we compared behavioral performance of control experiments (a vertex rTMS condition and two sham conditions, left parietal and right parietal sham) with baseline nonstimulation (see Materials and Methods). Stimulation of the vertex and both parietal sham conditions yielded no significant difference in accuracy and precision parameters relative to the baseline no rTMS condition in both saccade and reach tasks for all targets (see supplemental Fig. S4, available at www.jneurosci.org as supplemental material) (all $p$ values $>0.05$ ).

There were no significant differences in movement times between baseline (no rTMS) and parietal stimulation for any saccade or reach task (all $p$ values $>0.05$ ) (supplemental Fig. S5 $A, C$, available at www.jneurosci.org as supplemental material). In addition, analyses revealed no significant influence of parietal rTMS on reaction times (all $p$ values $>0.05$ ) (supplemental Fig. S5 B,D). Thus, our rTMS-induced effects on accuracy and precision could not be accounted for by differences in movement duration.

\section{Discussion}

Using on-line rTMS, the current study is the first to causally demonstrate regional effector (saccade vs reach) specificity in human PPC. Furthermore, we identified two distinct reach-related clusters: an 


\section{Reach Vision}

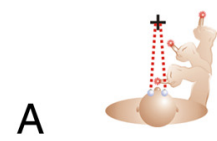

Right
Accuracy $30^{\circ} 20^{\circ} 10^{\circ} 0^{\circ} 10^{\circ} 20^{\circ} 30^{\circ}$ $000+000 \mathrm{D}$

$\mathrm{B}$

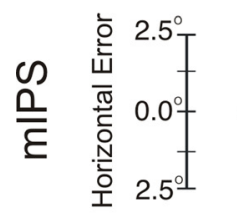

C

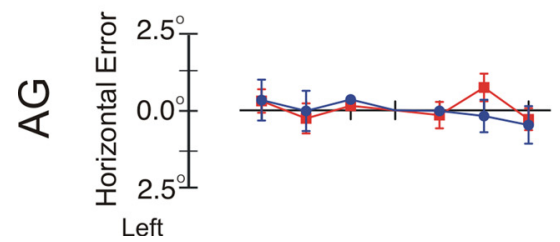

$E$

F

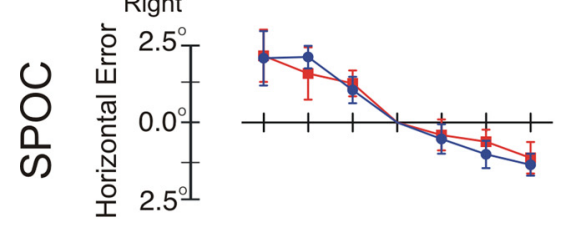

- No TMS

Left PPC

Right PPC
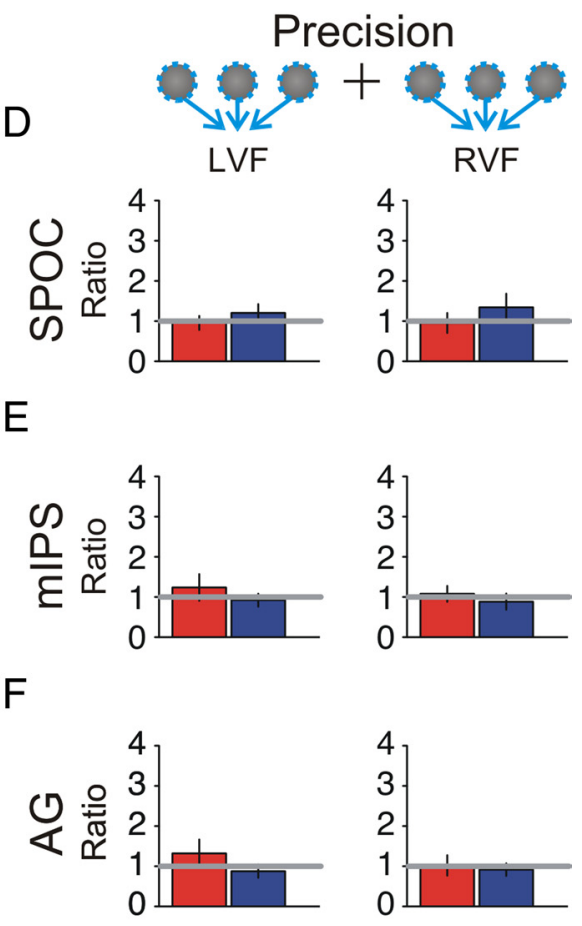
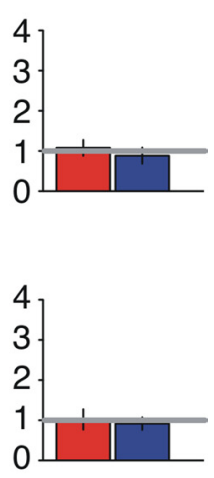

Figure 9. Experiment 3 reach accuracy and precision plots. $A-C$, Left, Reach accuracy with visual feedback of the hand. The magnitude of the rTMS-induced effects on horizontal error (relative to baseline no rTMS condition) is plotted for the $\operatorname{SPOC}(\boldsymbol{A})$, mIPS $(\boldsymbol{B})$, and $A G(\boldsymbol{C})$ in the leftPPC (solid red square and line) and right PPC (solid blue circle and line) for all subjects $(n=6) . \boldsymbol{D}-\boldsymbol{F}$, Right, Reach precision with visual feedback of the right hand. The precision ratio for the mean elliptical area for reach with visual feedback of the hand for baseline no rTMS trials (solid gray line) and both left PPC (solid red bar) and right PPC (solid blue bar) stimulation is shown in the LVF (left) and RVF (right) for the SPOC $(\boldsymbol{D}), \mathrm{mIPS}(\boldsymbol{E})$, and AG $(\boldsymbol{F})$. This figure follows the conventions of Figures 6 and 7. appears to be the analog of monkey LIP and MIP. Unit recordings in monkey show distinct, partially overlapping saccade and reach fields in these areas (Snyder et al., 1997; Battaglia-Mayer et al., 2001, 2003; Pesaran et al., 2006). Given the limited spatial resolution of rTMS, we cannot discount the possibility that human mIPS has the same underlying organization (Colby and Duhamel, 1991; Johnson et al., 1996; Snyder et al., 1997; Eskandar and Assad, 1999). Indeed, a patient with medial (but not lateral) IPS damage showed impaired visually guided reaching movements with preserved saccadic metrics (Trillenberg et al., 2007).

Our findings with SPOC are consistent with previous reports of directionally selective manual responses in humans (Astafiev et al., 2003; Connolly et al., 2003; Prado et al., 2005; Fernandez-Ruiz et al., 2007; Levy et al., 2007; Culham et al., 2008; Tosoni et al., 2008; Filimon et al., 2009) and reach specificity in monkey (V6A) (Galletti et al., 2003; Fattori et al., 2005, 2009). More compellingly, patients with damage to all three of these regions (mIPS, AG, SPOC) show deficits in both saccades (PierrotDeseilligny et al., 1991) and reach movements (Mattingley et al., 1998; Karnath and Perenin, 2005; Coulthard et al., 2006; Blangero et al., 2009; Himmelbach et al., 2009). anterior-lateral cluster (mIPS and AG) effect modulated by handedness and visual feedback of the hand, as opposed to a more posteriormedial (SPOC) effect modulated only by target eccentricity. Together, these findings suggest that human SPOC is specialized for encoding reach goals, whereas mIPS and AG are involved more closely in the motor planning of both saccades and reach.

\section{Cortical specificity for saccades vs reach}

Figure 11 provides a comparison between the stimulation sites used here and other fMRI, patient, and TMS studies in humans. Note that rTMS likely influences behavior by not only disrupting the targeted region, but its relevant network of functional connections (Sack, 2006; Driver et al., 2009). Taking this into account, our results showed clear site-specific behavioral deficits; thus, our TMS-induced disruption likely resides in the banks of IPS and parieto-occipital sulcus (Fox et al., 2004). In particular, mIPS and AG stimulation induced errors in both saccades and reach, whereas rTMS to SPOC disrupted only reach planning. These findings parallel the regional effector specificity that is observed in monkey PPC (Snyder et al., 1997; Andersen and Buneo, 2002) and provide clear causal evidence for effector specificity in human PPC (Astafiev et al., 2003; Connolly et al., 2003; Medendorp et al., 2003; Schluppeck et al., 2006; Hagler et al., 2007; Levy et al., 2007; Tosoni et al., 2008; Beurze et al., 2009; Van Der Werf et al., 2010).

The localization of mIPS and AG in our study is similar to saccade-, pointing-, and reach-related activity in previous human neuroimaging studies (DeSouza et al., 2000; Medendorp et al., 2003, 2005; Grefkes et al., 2004; Prado et al., 2005; Beurze et al., 2007, 2009; Hagler et al., 2007). Based on these data, human mIPS

\section{Hemispheric asymmetry in the rTMS effect on saccades}

As observed previously (Müri et al., 1996; Nyffeler et al., 2005), saccades were more sensitive to right PPC stimulation. It is possible that we simply missed the "parietal eye fields" in the left hemisphere, but this seems unlikely given the symmetry of results obtained in the fMRI studies that we used to target our pulses (see Fig. 11) and the expected spread of the rTMS effect (Driver et al., 2009; Wagner et al., 2009). Another explanation is that right PPC plays a critical role in both the control of saccades and spatial attention (Corbetta et al., 1998; Müri et al., 2000; Nobre et al., 2000; Rushworth et al., 2001; Chambers et al., 2004).

\section{Hand and visual hemifield specificity in mIPS and AG}

Stimulation of mIPS and AG produced the most robust effects on reach movements with the contralateral hand to the contralateral visual hemifield. It is possible that the inclusion of interspersed saccades in the right-hand reaching trials (but not left-hand trials) influenced our results. However, there is considerable support for our findings in the literature. First, previous TMS studies showed similar lateralized deficits in MIPS and AG for reaching (Desmurget et al., 1999; van Donkelaar and Adams, 2005) and rostral IPS for grasping (Rice et al., 2007). Second, a recent TMS study demonstrated that AG is critical in the early stages of planning contralateral reaches with the contralateral hand (Koch et al., 2008). Third, our hand/visual hemifield specificity is also consistent with neuronal activity found in monkeys (Chang et al., 2008) and BOLD activation in the mIPS and AG regions of human PPC (Medendorp et al., 2003, 2005; Beurze et al., 2007). Finally, our results are consistent with hand- and visual hemifield-specific deficits in optic ataxia (OA) (Perenin and 


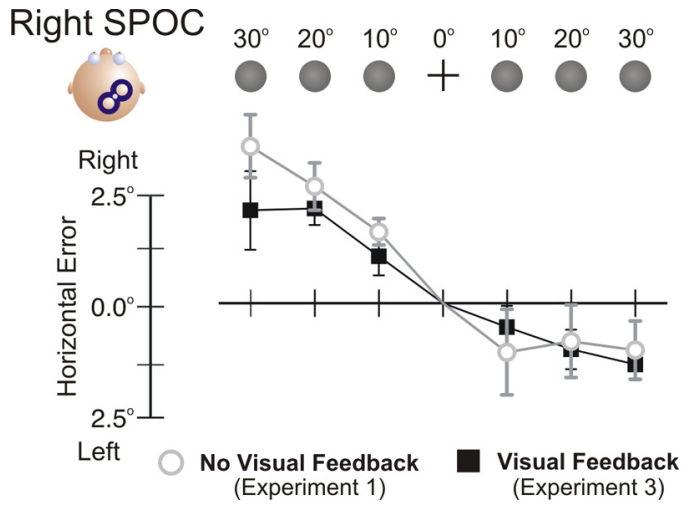

Figure 10. Comparison between data (magnitude of parietal rTMS-induced effects) obtained in experiment 1 (no visual feedback of hand) and experiment 3 (visual feedback of hand) for reaches with the right hand (same subjects, $n=6$ ). The figure plots the magnitude of the rTMS-induced effects (relative to their respective baseline no rTMS conditions) on accuracy for reaches with (open gray circle) and without (filled black square) visual feedback of the right hand for the right SPOC across targets. rTMS over the more posteriormedial region, $S P O C$, deviated end points similarly toward visual fixation, and they were not found to be significantly different for these visual conditions ( $p$ values for each target $>0.05)$. Error bars represent SE.

Vighetto, 1988; Rossetti et al., 2003; Blangero et al., 2007, 2008; Khan et al., 2007; Pisella et al., 2009) and directional motor impairments in neglect (Mattingley et al., 1998; Husain et al., 2000).

In contrast, rTMS over SPOC did not show lateralized effects. Lateralization in SPOC might have been negated by the spread of the magnetic field and/or induced electrical currents to the other hemisphere (left and right SPOC were only $2 \mathrm{~cm}$ apart) or distant, transcallosal effects (Ferbert et al., 1992; Ilmoniemi et al., 1997; Di Lazzaro et al., 1999; Siebner and Rothwell, 2003). However, fMRI and lesion data are consistent with the notion that there is a greater lateralization for contralateral hand movements in more anterior-lateral than medial-posterior foci that could explain the hand and field effect in OA reaching (Blangero et al., 2009).

\section{Goal encoding vs reach vector encoding}

The computation of reach vectors requires knowledge of both the desired goal and the initial hand positions, derived from either vision or proprioception, or both (Sober and Sabes, 2003, 2005; Khan et al., 2007). Our findings showing that visual feedback corrected errors induced by rTMS over AG (Vesia et al., 2008; current study) and mIPS (current study) suggest that these regions are involved in calculating the reach vector from the sense of initial hand position. This effect cannot be attributed to a perturbation of the internal representation of the reach goal, because goal feedback remains constant in both tasks. Monkey MIP possesses the necessary signals to compute the reach vector in gaze-centered coordinates (Batista et al., 1999; Chang et al., 2008, 2009). Human mIPS maintains a visual directional tuning after adaptation to left-right reversing prisms, whereas the spatial selectivity of AG remained fixed in somatosensory coordinates (Fernandez-Ruiz et al., 2007). Likewise, the directionality of reach errors during AG stimulation did not reverse after prism adaptation (Vesia et al., 2006). These findings suggest that mIPS and AG might be specific for the visual and somatosensory calculation of the reach vector, respectively.

In contrast, visual feedback of the hand did not correct reach errors induced by rTMS over SPOC, suggesting that this region is involved with goal encoding. Theoretically, it also is possible that this result is attributable to the disruption of a proprioceptive signal (or motor-related signals, like corollary discharges) that

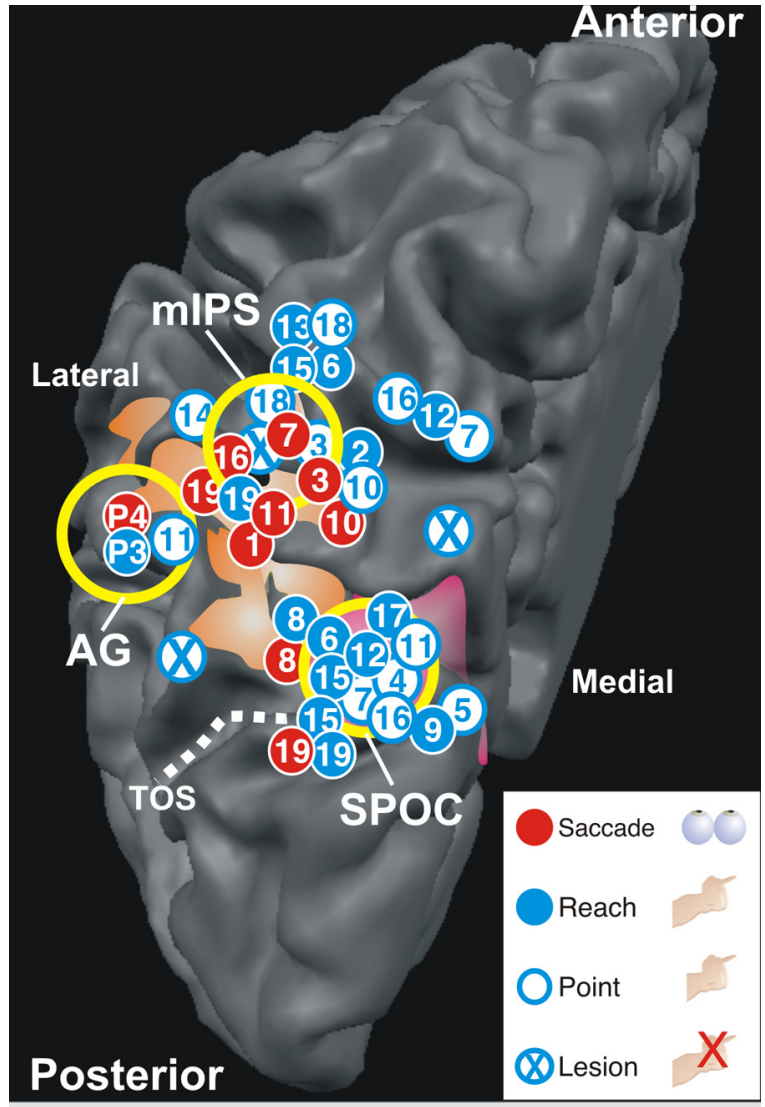

Intraparietal Sulcus

Parieto-occipital Sulcus

Figure 11. A comparison of fMRl, patient, and TMS studies. Three parietal sites were stimulated in current study (open yellow circles represent estimated stimulation areas): AG, mIPS, and $S P O C$, shown on a dorsomedial view of the left hemisphere. A summary of peak activation, lesion, and stimulation sites for saccade- (solid red circle), reach- (blue filled circle), and pointing-selective (open blue circle) regions identified in PPC by previous key studies in visuomotor control is listed below. Note that foci were based on reported Talairach coordinates transformed to surface locations on a subject's pial surface and represent averaged group peaks of activity, lesion overlap, and stimulation area [shaded orange area, intraparietal sulcus; shaded magenta area, parieto-occipital sulcus; dotted white line, temporal occipital sulcus (TOS)]. fMRI activation, lesion foci, and TMS sites are as follows: for saccade, 1 (Sereno et al., 2001; Merriam et al., 2003), 8 (Schluppeck, 2005; Schluppeck et al., 2006), P4 (Elkington et al., 1992; Müri et al., 1996, 2000; Kapoula et al., 2001; Yang and Kapoula, 2004; Nyffeler et al., 2005); for saccade and reach, 8 (Levy et al., 2007), 19 (Beurze et al., 2009); for saccade and point, 3 (Medendorp et al., 2003), 7 (Zettel et al., 2007), 10 (Hagler et al., 2007), 11 (FernandezRuiz et al., 2007), 16 (Tosoni et al., 2008); for reach, 2 (Pellijeff et al., 2006), 6 (Prado et al., 2005), 9 (Culham et al., 2008; Gallivan et al., 2009), 12 (Filimon et al., 2009), 13 (Beurze et al., 2007), 15 (Blangero et al., 2009), 17 (Busan et al., 2009a,b), P3 (van Donkelaar and Adams, 2005; Vesia et al., 2006, 2008; Koch et al., 2008); for point, 3 (Medendorp et al., 2005), 4 (Astafiev et al., 2003), 5 (Connolly et al., 2003), 14 (DeSouza et al., 2000); for eye-hand coordination, P3 (van Donkelaar et al., 2000); for joystick, P3 (Smyrnis et al., 2003), 18 (Grefkes et al., 2004); for lesion, $X$ (Karnath and Perenin, 2005).

cannot be recalibrated using a visual signal, but fMRI results suggest that in experiments like ours, SPOC encodes visual targets in retinal coordinates (Fernandez-Ruiz et al., 2007). Moreover, during rTMS over SPOC, we found that reach was deviated toward gaze (Figs. 6G, 9A). This resembles the gaze-dependent deviation in reaching induced by TMS over PPC by van Donkelaar and Adams (2005) and the inability of patients with OA (damage to PPC) to decouple reach from gaze (Carey et al., 1997; Jackson et al., 2005; Granek et al., 2009). This effect is expected if foveal representations are preserved at the expense of disrupted peripherally retinal representations (Crawford et al., 2004) and is 
consistent with selective activation of SPOC for peripherally retinal targets (Prado et al., 2005). Overall, our data suggest a computational distinction between the encoding of reach goals in SPOC and reach vectors in more anterior-lateral PPC sites.

\section{Conclusion}

Our results suggest that multiple, functionally distinct, and yet partially overlapping PPC regions play a crucial role in the planning of saccades and different aspects of reach. This functional segregation (i.e., mIPS vs SPOC) might subserve behaviors that require the decoupling of the eyes and hand (Henriques and Crawford, 2000, 2002; Gorbet et al., 2004; Prado et al., 2005; Gorbet and Sergio, 2009), whereas the overlap that was observed within mIPS and AG might subserve eye-hand coupling (Fisk and Goodale, 1985; Neggers and Bekkering, 2000, 2001; Johansson et al., 2001; Land and Hayhoe, 2001). Moreover, our data provide a plausible neuroanatomical substrate for understanding spatial deficits associated with saccade and reach planning after PPC damage.

\section{References}

Andersen RA, Buneo CA (2002) Intentional maps in posterior parietal cortex. Annu Rev Neurosci 25:189-220.

Andersen RA, Snyder LH, Bradley DC, Xing J (1997) Multimodal representation of space in the posterior parietal cortex and its use in planning movements. Annu Rev Neurosci 20:303-330.

Astafiev SV, Shulman GL, Stanley CM, Snyder AZ, Van Essen DC, Corbetta M (2003) Functional organization of human intraparietal and frontal cortex for attending, looking, and pointing. J Neurosci 23:4689-4699.

Batista AP, Buneo CA, Snyder LH, Andersen RA (1999) Reach plans in eyecentered coordinates. Science 285:257-260.

Battaglia-Mayer A, Ferraina S, Genovesio A, Marconi B, Squatrito S, Molinari M, Lacquaniti F, Caminiti R (2001) Eye-hand coordination during reaching. II. An analysis of the relationships between visuomanual signals in parietal cortex and parieto-frontal association projections. Cereb Cortex 11:528-544.

Battaglia-Mayer A, Caminiti R, Lacquaniti F, Zago M (2003) Multiple levels of representation of reaching in the parieto-frontal network. Cereb Cortex 13:1009-1022.

Bernier P-M, Burle B, Hasbroucq T, Blouin J (2009) Spatio-temporal dynamics of reach-related neural activity for visual and somatosensory targets. Neuroimage 47:1767-1777.

Bestmann S, Ruff CC, Blankenburg F, Weiskopf N, Driver J, Rothwell JC (2008) Mapping causal interregional influences with concurrent TMSfMRI. Exp Brain Res 191:383-402.

Beurze SM, de Lange FP, Toni I, Medendorp WP (2007) Integration of target and effector information in the human brain during reach planning. J Neurophysiol 97:188-199.

Beurze SM, de Lange FP, Toni I, Medendorp WP (2009) Spatial and effector processing in the human parietofrontal network for reaches and saccades. J Neurophysiol 101:3053-3062.

Blangero A, Ota H, Delporte L, Revol P, Vindras P, Rode G, Boisson D, Vighetto A, Rossetti Y, Pisella L (2007) Optic ataxia is not only "optic": impaired spatial integration of proprioceptive information. Neuroimage 36 [Suppl 2]:T61-T68.

Blangero A, Gaveau V, Luauté J, Rode G, Salemme R, Guinard M, Boisson D, Rossetti Y, Pisella L (2008) A hand and a field effect in on-line motor control in unilateral optic ataxia. Cortex 44:560-568.

Blangero A, Menz MM, McNamara A, Binkofski F (2009) Parietal modules for reaching. Neuropsychologia 47:1500-1507.

Bock O (1986) Contribution of retinal versus extraretinal signals towards visual localization in goal-directed movements. Exp Brain Res 64: $476-482$.

Boroojerdi B, Meister IG, Foltys H, Sparing R, Cohen LG, Topper R (2002) Visual and motor cortex excitability: a transcranial magnetic stimulation study. Clin Neurophysiol 113:1501-1504.

Brasil-Neto JP, Cohen LG, Panizza M, Nilsson J, Roth BJ, Hallett M (1992) Optimal focal transcranial magnetic activation of the human motor cortex: effects of coil orientation, shape of the induced current pulse, and stimulus intensity. J Clin Neurophysiol 9:132-136.

Buelte D, Meister IG, Staedtgen M, Dambeck N, Sparing R, Grefkes C,
Boroojerdi B (2008) The role of the anterior intraparietal sulcus in crossmodal processing of object features in humans: an rTMS study. Brain Res 1217:110-118.

Busan P, Monti F, Semenic M, Pizzolato G, Battaglini PP (2009a) Parietooccipital cortex and planning of reaching movements: a transcranial magnetic stimulation study. Behav Brain Res 201:112-119.

Busan P, Barbera C, Semenic M, Monti F, Pizzolato G, Pelamatti G, Battaglini PP (2009b) Effect of transcranial magnetic stimulation (TMS) on parietal and premotor cortex during planning of reaching movements. PLoS One 4:e4621.

Calton JL, Dickinson AR, Snyder LH (2002) Non-spatial, motor-specific activation in posterior parietal cortex. Nat Neurosci 5:580-588.

Carey DP, Coleman RJ, Della Sala S (1997) Magnetic misreaching. Cortex 33:639-652.

Chambers CD, Payne JM, Stokes MG, Mattingley JB (2004) Fast and slow parietal pathways mediate spatial attention. Nat Neurosci 7:217-218.

Chang SW, Dickinson AR, Snyder LH (2008) Limb-specific representation for reaching in the posterior parietal cortex. J Neurosci 28:6128-6140.

Chang SW, Papadimitriou C, Snyder LH (2009) Using a compound gain field to compute a reach plan. Neuron 64:744-755.

Colby CL, Duhamel JR (1991) Heterogeneity of extrastriate visual areas and multiple parietal areas in the macaque monkey. Neuropsychologia 29:517-537.

Colby CL, Goldberg ME (1999) Space and attention in parietal cortex. Annu Rev Neurosci 22:319-349.

Connolly JD, Andersen RA, Goodale MA (2003) FMRI evidence for a "parietal reach region" in the human brain. Exp Brain Res 153:140-145.

Corbetta M, Akbudak E, Conturo TE, Snyder AZ, Ollinger JM, Drury HA, Linenweber MR, Petersen SE, Raichle ME, Van Essen DC, Shulman GL (1998) A common network of functional areas for attention and eye movements. Neuron 21:761-773.

Coulthard E, Parton A, Husain M (2006) Action control in visual neglect. Neuropsychologia 44:2717-2733.

Crawford JD, Medendorp WP, Marotta JJ (2004) Spatial transformations for eye-hand coordination. J Neurophysiol 92:10-19.

Culham JC, Valyear K (2006) Human parietal cortex in action. Curr Opin Neurobiol 16:205-212.

Culham JC, Cavina-Pratesi C, Singhal A (2006) The role of parietal cortex in visuomotor control: what have we learned from neuroimaging? Neuropsychologia 44:2668-2684.

Culham JC, Gallivan J, Cavina-Pratesi C, Quinlan DJ (2008) fMRI investigations of reaching and ego space in human superior parieto-occipital cortex. In: Embodiment, ego-space and action (Klatzky R, McWhinney B, Behrmann M, eds), pp 247-274. New York: Psychology.

Dambeck N, Sparing R, Meister IG, Wienemann M, Weidemann J, Topper R, Boroojerdi B (2006) Interhemispheric imbalance during visuospatial attention investigated by unilateral and bilateral TMS over human parietal cortices. Brain Res 1072:194-199.

Desmurget M, Epstein CM, Turner RS, Prablanc C, Alexander GE, Grafton ST (1999) Role of the posterior parietal cortex in updating reaching movements to a visual target. Nat Neurosci 2:563-567.

DeSouza JF, Dukelow SP, Gati JS, Menon RS, Andersen RA, Vilis T (2000) Eye position signal modulates a human parietal pointing region during memory-guided movements. J Neurosci 20:5835-5840.

Di Lazzaro V, Oliviero A, Profice P, Insola A, Mazzone P, Tonali P, Rothwell JC (1999) Direct demonstration of interhemispheric inhibition of the human motor cortex produced by transcranial magnetic stimulation. Exp Brain Res 124:520-524.

Driver J, Blankenburg F, Bestmann S, Vanduffel W, Ruff CC (2009) Concurrent brain-stimulation and neuroimaging for studies of cognition. Trends Cogn Sci 13:319-327.

Elkington PT, Kerr GK, Stein JS (1992) The effect of electromagnetic stimulation of the posterior parietal cortex on eye movements. Eye 6:510-514.

Epstein CM, Schwartzberg DG, Davey KR, Sudderth DB (1990) Localizing the site of magnetic brain stimulation in humans. Neurology 40:666-670.

Eskandar EN, Assad JA (1999) Dissociation of visual, motor and predictive signals in parietal cortex during visual guidance. Nat Neurosci 2:88-93.

Fattori P, Kutz DF, Breveglieri R, Marzocchi N, Galletti C (2005) Spatial tuning of reaching activity in the medial parieto-occipital cortex (area V6A) of macaque monkey. Eur J Neurosci 22:956-972.

Fattori P, Breveglieri R, Marzocchi N, Filippini D, Bosco A, Galletti C (2009) 
Hand orientation during reach-to-grasp movements modulates neuronal activity in the medial posterior parietal area V6A. J Neurosci 29: $1928-1936$.

Ferbert A, Priori A, Rothwell JC, Day BL, Colebatch JG, Marsden CD (1992) Interhemispheric inhibition of the human motor cortex. J Physiol 453: 525-546.

Fernandez-Ruiz J, Goltz HC, DeSouza JFX, Vilis T, Crawford JD (2007) Human parietal "reach region" primarily encodes intrinsic visual direction, not extrinsic movement direction, in a visual motor dissociation task. Cereb Cortex 17:2283-2292.

Filimon F, Nelson JD, Huang RS, Sereno MI (2009) Multiple parietal reach regions in humans: cortical representations for visual and proprioceptive feedback during on-line reaching. J Neurosci 29:2961-2971.

Fisk JD, Goodale MA (1985) The organization of eye and limb movements during unrestricted reaching to targets in contralateral and ipsilateral visual space. Exp Brain Res 60:159-178.

Fox PT, Narayana S, Tandon N, Sandoval H, Fox SP, Kochunov P, Lancaster JL (2004) Column-based model of electric field excitation of cerebral cortex. Hum Brain Mapp 22:1-14.

Galletti C, Kutz DF, Gamberini M, Breveglieri R, Fattori P (2003) Role of the medial parieto-occipital cortex in the control of reaching and grasping movements. Exp Brain Res 153:158-170.

Gallivan JP, Cavina-Pratesi C, Culham JC (2009) Is that within reach? fMRI reveals that the human superior parieto-occipital cortex encodes objects reachable by the hand. J Neurosci 29:4381-4391.

Goodale MA, Milner AD (1992) Separate visual pathways for perception and action. Trends Neurosci 15:20-25.

Gorbet DJ, Sergio LE (2009) The behavioural consequences of dissociating the spatial directions of eye and arm movements. Brain Res 1284:77-88.

Gorbet DJ, Staines WR, Sergio LE (2004) Brain mechanisms for preparing increasingly complex sensory to motor transformations. Neuroimage 23:1100-1111.

Granek JA, Blangero A, Pisella L, Rossetti Y, Sergio LE (2009) Patients with optic ataxia cannot decouple eye and hand movements when performing complex visuomotor tasks. Soc Neurosci Abstr 35:354.20/Y8.

Grefkes C, Fink GR (2005) The functional organization of the intraparietal sulcus in humans and monkeys. J Anat 207:3-17.

Grefkes C, Ritzl A, Zilles K, Fink GR (2004) Human medial intraparietal cortex subserves visuomotor coordinate transformation. Neuroimage 23:1494-1506.

Hagler DJ, Riecke L, Sereno MI (2007) Parietal and superior frontal visuospatial maps activated by pointing and saccades. Neuroimage 35: $1562-1577$.

Hallett M (2000) Transcranial magnetic stimulation and the human brain. Nature 406:147-150.

Henriques DY, Crawford JD (2000) Direction-dependent distortions of retinocentric space in the visuomotor transformation for pointing. Exp Brain Res 132:179-194.

Henriques DY, Crawford JD (2002) Role of eye, head, and shoulder geometry in the planning of accurate arm movements. J Neurophysiol 87:1677-1685.

Henriques DY, Klier EM, Smith MA, Lowy D, Crawford JD (1998) Gazecentered remapping of remembered visual space in an open-loop pointing task. J Neurosci 18:1583-1594.

Herwig U, Satrapi P, Schonfeldt-Lecuona C (2003) Using the international 10-20 EEG system for positioning of transcranial magnetic stimulation. Brain Topogr 16:95-99.

Himmelbach M, Nau M, Zündorf I, Erb M, Perenin M, Karnath H (2009) Brain activation during immediate and delayed reaching in optic ataxia. Neuropsychologia 47:1508-1517.

Husain M, Mattingley JB, Rorden C, Kennard C, Driver J (2000) Distinguishing sensory and motor biases in parietal and frontal neglect. Brain 123:1643-1659.

Ilmoniemi RJ, Virtanen J, Ruohonen J, Karhu J, Aronen HJ, Näätänen R, Katila T (1997) Neuronal responses to magnetic stimulation reveal cortical reactivity and connectivity. Neuroreport 8:3537-3540.

Jackson SR, Newport R, Mort D, Husain M (2005) Where the eye looks, the hand follows: limb-dependent magnetic misreaching in optic ataxia. Curr Biol 15:42-46.

Jeannerod M, Arbib MA, Rizzolatti G, Sakata H (1995) Grasping objects: the cortical mechanisms of visuomotor transformation. Trends Neurosci 18:314-320.
Johansson RS, Westling G, Bäckström A, Flanagan JR (2001) Eye-hand coordination in object manipulation. J Neurosci 21:6917-6932.

Johnson PB, Ferraina S, Bianchi L, Caminiti R (1996) Cortical networks for visual reaching: physiological and anatomical organization of frontal and parietal lobe arm regions. Cereb Cortex 6:102-119.

Kalaska JF, Scott SH, Cisek P, Sergio LE (1997) Cortical control of reaching movements. Curr Opin Neurobiol 7:849-859.

Kapoula Z, Isotalo E, Müri RM, Bucci MP, Rivaud-Péchoux S (2001) Effects of transcranial magnetic stimulation of the posterior parietal cortex on saccades and vergence. Neuroreport 12:4041-4046.

Karnath HO, Perenin MT (2005) Cortical control of visually guided reaching: evidence from patients with optic ataxia. Cereb Cortex 15:1561-1569.

Keel JC, Smith MJ, Wassermann EM (2001) A safety screening questionnaire for transcranial magnetic stimulation. Clin Neurophysiol 112:720.

Khan AZ, Crawford JD, Blohm G, Urquizar C, Rossetti Y, Pisella L (2007) Influence of initial hand and target position on reach errors in optic ataxic and normal subjects. J Vis 7:1-16.

Koch G, Del Olmo MF, Cheeran B, Schippling S, Caltagirone C, Driver J, Rothwell JC (2008) Functional interplay between posterior parietal and ipsilateral motor cortex revealed by twin-coil transcranial magnetic stimulation during reach planning toward contralateral space. J Neurosci 28:5944-5953.

Land MF, Hayhoe M (2001) In what ways do eye movements contribute to everyday activities? Vision Res 41:3559-3565.

Levkovitz Y, Marx J, Grisaru N, Segal M (1999) Long-term effects of transcranial magnetic stimulation on hippocampal reactivity to afferent stimulation. J Neurosci 19:3198-3203.

Levy I, Schluppeck D, Heeger DJ, Glimcher PW (2007) Specificity of human cortical areas for reaches and saccades. J Neurosci 27:4687-4696.

Lewald J, Foltys H, Topper R (2002) Role of the posterior parietal cortex in spatial hearing. J Neurosci 22:RC207.

Logothetis NK (2008) What we can do and what we cannot do with fMRI. Nature 453:869-878.

Machii K, Cohen D, Ramosestebanez C, Pascualleone A (2006) Safety of rTMS to non-motor cortical areas in healthy participants and patients. Clin Neurophysiol 117:455-471.

Mattingley JB, Husain M, Rorden C, Kennard C, Driver J (1998) Motor role of human inferior parietal lobe revealed in unilateral neglect patients. Nature 392:179-182.

Medendorp WP, Crawford JD (2002) Visuospatial updating of reaching targets in near and far space. Neuroreport 13:633-636.

Medendorp WP, Goltz HC, Vilis T, Crawford JD (2003) Gaze-centered updating of visual space in human parietal cortex. J Neurosci 23:6209-6214.

Medendorp WP, Goltz HC, Crawford JD, Vilis T (2005) Integration of target and effector information in human posterior parietal cortex for the planning of action. J Neurophysiol 93:954-962.

Merriam EP, Genovese CR, Colby CL (2003) Spatial updating in human parietal cortex. Neuron 39:361-373.

Müri RM, Vermersch AI, Rivaud S, Gaymard B, Pierrot-Deseilligny C (1996) Effects of single-pulse transcranial magnetic stimulation over the prefrontal and posterior parietal cortices during memory-guided saccades in humans. J Neurophysiol 76:2102-2106.

Müri RM, Gaymard B, Rivaud S, Vermersch A, Hess CW, Pierrot-Deseilligny C (2000) Hemispheric asymmetry in cortical control of memory-guided saccades. A transcranial magnetic stimulation study. Neuropsychologia 38:1105-1111.

Neggers SF, Bekkering H (2000) Ocular gaze is anchored to the target of an ongoing pointing movement. J Neurophysiol 83:639-651.

Neggers SF, Bekkering H (2001) Gaze anchoring to a pointing target is present during the entire pointing movement and is driven by a nonvisual signal. J Neurophysiol 86:961-970.

Nobre AC, Gitelman DR, Dias EC, Mesulam MM (2000) Covert visual spatial orienting and saccades: overlapping neural systems. Neuroimage 11:210-216.

Nyffeler T, Egli A, Pflugshaupt T, Von Wartburg R, Wurtz P, Mosimann U, Hess CW, Müri RM (2005) The role of the human posterior parietal cortex in memory-guided saccade execution: a double-pulse transcranial magnetic stimulation study. Eur J Neurosci 22:535-538.

Okamoto M, Dan H, Sakamoto K, Takeo K, Shimizu K, Kohno S, Oda I, Isobe S, Suzuki T, Kohyama K, Dan I (2004) Three-dimensional probabilistic anatomical cranio-cerebral correlation via the international 10-20 sys- 
tem oriented for transcranial functional brain mapping. Neuroimage 21:99-111.

Oldfield RC (1971) The assessment and analysis of handedness: the Edinburgh inventory. Neuropsychologia 9:97-113.

Oliver R, Bjoertomt O, Driver J, Greenwood R, Rothwell J (2009) Novel "hunting" method using transcranial magnetic stimulation over parietal cortex disrupts visuospatial sensitivity in relation to motor thresholds. Neuropsychologia 47:3152-3161.

Oyachi H, Ohtsuka K (1995) Transcranial magnetic stimulation of the posterior parietal cortex degrades accuracy of memory-guided saccades in humans. Investigative Ophthalmol Vis Sci 36:1441-1449.

Pascual-Leone A, Valls-Sole J, Wassermann EM, Hallett M (1994) Responses to rapid-rate transcranial magnetic stimulation of the human motor cortex. Brain 117:847-858.

Pellijeff A, Bonilha L, Morgan P, Mckenzie K, Jackson S (2006) Parietal updating of limb posture: An event-related fMRI study. Neuropsychologia 44:2685-2690.

Perenin MT, Vighetto A (1988) Optic ataxia: a specific disruption in visuomotor mechanisms. I. Different aspects of the deficit in reaching for objects. Brain 111:643-674.

Pesaran B, Nelson M, Andersen R (2006) Dorsal premotor neurons encode the relative position of the hand, eye, and goal during reach planning. Neuron 51:125-134.

Pierrot-Deseilligny C, Rivaud S, Gaymard B, Agid Y (1991) Cortical control of memory-guided saccades in man. Exp Brain Res 83:607-617.

Pisella L, Sergio L, Blangero A, Torchin H, Vighetto A, Rossetti Y (2009) Optic ataxia and the function of the dorsal stream: contributions to perception and action. Neuropsychologia 47:3033-3044.

Poljac E, Van Den Berg AV (2003) Representation of heading direction in far and near head space. Exp Brain Res 151:501-513.

Pouget A, Ducom JC, Torri J, Bavelier D (2002) Multisensory spatial representations in eye-centered coordinates for reaching. Cognition 83:B1-B11.

Prado J, Clavagnier S, Otzenberger H, Scheiber C, Kennedy H, Perenin M-T (2005) Two cortical systems for reaching in central and peripheral vision. Neuron 48:849-858.

Prime SL, Vesia M, Crawford JD (2008) Transcranial magnetic stimulation over posterior parietal cortex disrupts transsaccadic memory of multiple objects. J Neurosci 28:6938-6949.

Ren L, Cressman E, Blohm G, Cheyne D, Crawford J (2008) Cortical activation during visual memory-guided and hand-guided saccades: an MEG study. Soc Neurosci Abstr 34:17.1.

Rice N, Tunik E, Cross E, Grafton S (2007) On-line grasp control is mediated by the contralateral hemisphere. Brain Res 1175:76-84.

Robertson EM, Théoret H, Pascual-Leone A (2003) Studies in cognition: the problems solved and created by transcranial magnetic stimulation. J Cogn Neurosci 15:948-960.

Rossetti Y, Pisella L, Vighetto A (2003) Optic ataxia revisited: Visually guided action versus immediate visuomotor control. Exp Brain Res 153:171-179.

Rossi S, Hallett M, Rossini PM, Pascual-Leone A, Safety of TMS Consensus Group SoTC (2009) Safety, ethical considerations, and application guidelines for the use of transcranial magnetic stimulation in clinical practice and research. Clin Neurophysiol 120:2008-2039.

Rudiak D, Marg E (1994) Finding the depth of magnetic brain stimulation: a re-evaluation. Electroencephalogr Clin Neurophysiol 93:358-371.

Ruff C, Driver J, Bestmann S (2009) Combining TMS and fMRI: From "virtual lesions" to functional-network accounts of cognition. Cortex 45:1043-1049.

Rushworth MF, Ellison A, Walsh V (2001) Complementary localization and lateralization of orienting and motor attention. Nat Neurosci 4:656-661.

Ryan S, Bonilha L, Jackson SR (2006) Individual variation in the location of the parietal eye fields: a TMS study. Exp Brain Res 173:389-394.

Sack AT (2006) Transcranial magnetic stimulation, causal structurefunction mapping and networks of functional relevance. Curr Opin Neurobiol 16:593-599.

Schluppeck D (2005) Topographic organization for delayed saccades in human posterior parietal cortex. J Neurophysiol 94:1372-1384.

Schluppeck D, Curtis CE, Glimcher PW, Heeger DJ (2006) Sustained activity in topographic areas of human posterior parietal cortex during memory-guided saccades. J Neurosci 26:5098-5108.

Sereno MI, Pitzalis S, Martinez A (2001) Mapping of contralateral space in retinotopic coordinates by a parietal cortical area in humans. Science 294:1350-1354.

Siebner H, Rothwell J (2003) Transcranial magnetic stimulation: new insights into representational cortical plasticity. Exp Brain Res 148:1-16.

Siebner HR, Hartwigsen G, Kassuba T, Rothwell JC (2009) How does transcranial magnetic stimulation modify neuronal activity in the brain? Implications for studies of cognition. Cortex 45:1035-1042.

Smyrnis N, Theleritis C, Evdokimidis I, Müri RM, Karandreas N (2003) Single-pulse transcranial magnetic stimulation of parietal and prefrontal areas in a memory delay arm pointing task. J Neurophysiol 89:3344-3350.

Snyder LH, Batista AP, Andersen RA (1997) Coding of intention in the posterior parietal cortex. Nature 386:167-170.

Snyder LH, Batista AP, Andersen RA (2000) Saccade-related activity in the parietal reach region. J Neurophysiol 83:1099-1102.

Sober SJ, Sabes PN (2003) Multisensory integration during motor planning. J Neurosci 23:6982-6992.

Sober SJ, Sabes PN (2005) Flexible strategies for sensory integration during motor planning. Nat Neurosci 8:490-497.

Stewart LM, Walsh V, Rothwell JC (2001) Motor and phosphene thresholds: a transcranial magnetic stimulation correlation study. Neuropsychologia 39:415-419.

Stokes MG, Chambers CD, Gould IC, Henderson TR, Janko NE, Allen NB, Mattingley JB (2005) Simple metric for scaling motor threshold based on scalp-cortex distance: application to studies using transcranial magnetic stimulation. J Neurophysiol 94:4520-4527.

Talairach J, Tournoux P (1988) Co-planar stereotaxic atlas of the human brain: 3-dimensional proportional system: an approach to cerebral imaging. Stuttgart, NY: Thieme Medical.

Tosoni A, Galati G, Romani GL, Corbetta M (2008) Sensory-motor mechanisms in human parietal cortex underlie arbitrary visual decisions. Nat Neurosci 11:1446-1453.

Trillenberg P, Sprenger A, Petersen D, Kömpf D, Heide W, Helmchen C (2007) Functional dissociation of saccade and hand reaching control with bilateral lesions of the medial wall of the intraparietal sulcus: implications for optic ataxia. Neuroimage 36 [Suppl 2]:T69-T76.

Van Der Werf J, Jensen O, Fries P, Medendorp WP (2010) Neuronal synchronization in human posterior parietal cortex during reach planning. J Neurosci 30:1402-1412.

van Donkelaar P, Adams J (2005) Gaze-dependent deviation in pointing induced by transcranial magnetic stimulation over the human posterior parietal cortex. J Motor Behav 37:157-163.

van Donkelaar P, Lee JH, Drew AS (2000) Transcranial magnetic stimulation disrupts eye-hand interactions in the posterior parietal cortex. J Neurophysiol 84:1677-1680.

van Donkelaar P, Lee JH, Drew AS (2002) Cortical frames of reference for eye-hand coordination. Prog Brain Res 140:301-310.

Vesia M, Monteon JA, Sergio LE, Crawford JD (2006) Hemispheric asymmetry in memory-guided pointing during single-pulse transcranial magnetic stimulation of human parietal cortex. J Neurophysiol 96:3016-3027.

Vesia M, Yan X, Henriques DY, Sergio LE, Crawford JD (2008) Transcranial magnetic stimulation over human dorsal-lateral posterior parietal cortex disrupts integration of hand position signals into the reach plan. J Neurophysiol 100:2005-2014.

Wagner T, Rushmore J, Eden U, Valero-Cabre A (2009) Biophysical foundations underlying TMS: setting the stage for an effective use of neurostimulation in the cognitive neurosciences. Cortex 45:1025-1034.

Wang H, Wang X, Scheich H (1996) LTD and LTP induced by transcranial magnetic stimulation in auditory cortex. Neuroreport 7:521-525.

Wassermann EM (1998) Risk and safety of repetitive transcranial magnetic stimulation: report and suggested guidelines from the International Workshop on the Safety of Repetitive Transcranial Magnetic Stimulation, June 5-7, 1996. Electroencephalogr Clin Neurophysiol 108:1-16.

Wilson SA, Thickbroom GW, Mastaglia FL (1993) Transcranial magnetic stimulation mapping of the motor cortex in normal subjects. The representation of two intrinsic hand muscles. J Neurol Sci 118:134-144.

Yang Q, Kapoula Z (2004) TMS over the left posterior parietal cortex prolongs latency of contralateral saccades and convergence. Invest Ophthalmol Vis Sci 45:2231-2239.

Zettel JL, Culham J, Vilis T, Crawford JD (2007) A comparison of saccade and pointing topography in the human posterior parietal cortex. Soc Neurosci Abstr 33:508.12. 